Article

\title{
Comparative Transcriptome Analysis of Rutabaga (Brassica napus) Cultivars Indicates Activation of Salicylic Acid and Ethylene-Mediated Defenses in Response to Plasmodiophora brassicae
}

\author{
Qinqin Zhou, Leonardo Galindo-González@, Victor Manolii, Sheau-Fang Hwang \\ and Stephen E. Strelkov *(D) \\ Department of Agricultural, Food and Nutritional Science, University of Alberta, \\ Edmonton, AB T6G 2P5, Canada; qinqin@ualberta.ca (Q.Z.); galindo@ualberta.ca (L.G.-G.); \\ vmanolii@ualberta.ca (V.M.); sheau.fang.hwang@ualberta.ca (S.-F.H.) \\ * Correspondence: strelkov@ualberta.ca; Tel.: +1-(780)-492-1969
}

Received: 16 September 2020; Accepted: 4 November 2020; Published: 8 November 2020

check for updates

\begin{abstract}
Clubroot, caused by Plasmodiophora brassicae Woronin, is an important soilborne disease of Brassica napus L. and other crucifers. To improve understanding of the mechanisms of resistance and pathogenesis in the clubroot pathosystem, the rutabaga (B. napus subsp. rapifera Metzg) cultivars 'Wilhelmsburger' (resistant) and 'Laurentian' (susceptible) were inoculated with P. brassicae pathotype $3 \mathrm{~A}$ and their transcriptomes were analyzed at 7, 14, and 21 days after inoculation (dai) by RNA sequencing (RNA-seq). Thousands of transcripts with significant changes in expression were identified in each host at each time-point in inoculated vs. non-inoculated plants. Molecular responses at 7 and 14 dai supported clear differences in the clubroot response mechanisms of the two genotypes. Both the resistant and the susceptible cultivars activated receptor-like protein $(R L P)$ genes, resistance $(R)$ genes, and genes involved in salicylic acid (SA) signaling as clubroot defense mechanisms. In addition, genes related to calcium signaling and genes encoding leucine-rich repeat (LRR) receptor kinases, the respiratory burst oxidase homolog $(\mathrm{RBOH})$ protein, and transcription factors such as WRKYs, ethylene responsive factors, and basic leucine zippers (bZIPs), appeared to be upregulated in 'Wilhelmsburger' to restrict P. brassicae development. Some of these genes are essential components of molecular defenses, including ethylene (ET) signaling and the oxidative burst. Our study highlights the importance of activation of genes associated with SA- and ET-mediated responses in the resistant cultivar. A set of candidate genes showing contrasting patterns of expression between the resistant and susceptible cultivars was identified and includes potential targets for further study and validation through approaches such as gene editing.
\end{abstract}

Keywords: Brassica napus; Plasmodiophora brassicae; clubroot; RNA sequencing (RNA-seq); defense mechanisms; salicylic acid; ethylene

\section{Introduction}

Clubroot, caused by the obligate parasite Plasmodiophora brassicae Woronin, is an important soilborne disease of Brassica crops. Susceptible plants develop characteristic root galls following infection, which interrupt water and nutrient uptake and result in significant yield and quality losses. Globally, losses from clubroot have been estimated at 10-15\% [1]. In Canada, the disease has long been an issue on cruciferous vegetables [2], and since the early 2000s has emerged as an important constraint to the production of canola (oilseed rape; Brassica napus L.) [3]. As canola is one of the most valuable crops for Canadian farmers, contributing $\$ 26.7$ billion CAD annually to the national economy [4], 
there have been significant efforts to improve the understanding and management of this disease. While numerous control strategies have been evaluated, including long rotations out of susceptible hosts and the application of soil amendments to reduce disease pressure $[5,6]$, the deployment of genetically resistant canola cultivars remains the backbone of clubroot management [7].

The first clubroot resistant (CR) canola cultivars were introduced to Canada in 2009-2010, and at present there are about $30 \mathrm{CR}$ varieties from various seed companies on the market [8]. The basis of this resistance, however, appears to be similar across most cultivars, and is derived from the European winter B. napus 'Mendel' [9]. Although 'Mendel'-type resistance initially provided excellent protection against all pathotypes of P. brassicae known in Canada, it was first overcome in 2013 [10], just four years after its introduction. Subsequent studies have documented the loss or erosion of resistance in an increasing number of fields, likely because of selection pressure imposed by CR canola on P. brassicae populations [11,12]. This has resulted in the emergence of multiple 'novel' pathotypes of $P$. brassicae that are highly virulent on CR canola; among these, pathotype $3 \mathrm{~A}$, as defined on the Canadian Clubroot Differential (CCD) set, is predominant in western Canada, where most canola is grown [11]. New sources of clubroot resistance, combined with other management strategies and better understanding of resistance mechanisms, will improve long-term control of this disease.

Plants have a two-layer immune system for defense against pathogen attack. Pathogen-associated molecular pattern (PAMP)-triggered immunity (PTI) is the first line of defense to generic pathogen signals [13]. This first line of defense is initiated by pattern recognition receptors (PRRs), usually receptor kinases and receptor-like proteins (RLPs), which recognize evolutionarily conserved PAMPs or endogenous damage-associated molecular patterns (DAMPs) [14]. Pathogens can, however, suppress PTI and facilitate virulence via the production of specific effectors. These effectors can be detected by specific resistance $(R)$ genes in the plant in a "gene-for-gene" type interaction, activating the second layer of immunity, called effector-triggered immunity (ETI) [13]. The $R$-gene response has been studied more extensively in the clubroot pathosystem and has proven important for resistance to this disease. For example, two clubroot resistance genes, $C R a$ and $C r r 1$, cloned in $B$. rapa, encode Toll-interleukin receptor nucleotide-binding site leucine-rich repeat (TIR-NBS-LRR) proteins, characterized as $R$ genes $[15,16]$. In each of B. napus, B. oleracea, and B. rapa, around 10-20 quantitative resistance loci (QTL) have been mapped for clubroot resistance [17]. Various additional $R$ genes have been identified in clubroot resistance loci in B. rapa, including Crd, Rcr1, Rcr2, Rcr4, Rcr6, Rcr8, and Rcr9 [18-22], which could be important resources for resistance breeding. Recently, there has been increasing interest in identifying and utilizing PTI-related genes in QTL to achieve long-term resistance to many diseases [23]. Therefore, key resistance regulators beyond $R$ genes also have the potential for use in clubroot resistance breeding programs.

Transcriptomic analyses have been conducted with increasing frequency in the study of P. brassicae-host interactions. For instance, recent transcriptomic studies of the responses of $B$. rapa and $B$. juncea to the clubroot pathogen have suggested the involvement of PTI and ETI in resistant reactions. These responses included the activation of genes encoding PRRs, R proteins, mitogen-activated protein kinases (MAPK), transcription factors (TFs), pathogenesis-related (PR) proteins, as well as genes involved in cell wall modification, calcium, and hormone signaling, and the production of reactive oxygen species (ROS) [24,25]. In another study comparing the transcriptomes of clubroot susceptible (CS) and CR B. napus lines carrying resistance introgressed from rutabaga (B. napus subsp. rapifera Metzg), long noncoding RNAs appeared to be involved in regulating target genes involved in the plant-pathogen interaction, hormone signaling, and primary/secondary metabolism in response to P. brassicae [26]. Studies with rutabaga are particularly relevant for understanding the interaction between the clubroot pathogen and canola, since rutabaga is a source of resistance for the latter [27-30].

A recent study investigating the transcriptomes of $B$. napus cultivars with differential resistance to $P$. brassicae pathotype $5 \mathrm{X}$ indicated the involvement of salicylic acid (SA)-mediated immunity in the resistance expressed by the cultivar 'Laurentian' [31]. This cultivar, however, is susceptible to pathotype $3 \mathrm{~A}$, the predominant resistance-breaking pathotype in western Canada [11]. In the current 
study, to better understand host responses to P. brassicae and identify candidate genes for canola clubroot resistance breeding, we challenged the rutabagas 'Wilhelmsburger' and 'Laurentian' with pathotype $3 \mathrm{~A}$ of $P$. brassicae and compared their transcriptomic responses at multiple time-points during secondary infection. Both the resistant ('Wilhelmsburger') and susceptible ('Laurentian') cultivars activated $R L P$ genes, $R$ genes, and genes involved in SA synthesis and signaling, in response to the pathogen. The resistant host, however, also appeared to coordinate the activity of genes involved in various additional pathways, including ethylene (ET) signaling. This study provides insights on possible common defense responses mediated by rutabaga cultivars against pathotype $3 \mathrm{~A}$, and highlights the molecular defense mechanisms in a specific host ('Wilhelmsburger') that could be involved in resistance. Several key genes were identified that may serve as good candidates for future clubroot resistance breeding studies, including functional validation and increased resistance through gene editing.

\section{Results and Discussion}

\subsection{Disease Assessment}

Clubroot development in both host cultivars following P. brassicae inoculation was evaluated based on the severity of root galling. Noticeable galls appeared 14 dai in 'Laurentian' but were not visible in 'Wilhelmsburger' until 21 dai (Figure 1). At 45 dai, the disease index (DI) on 'Laurentian' was 99\%, indicating complete susceptibility, while on 'Wilhelmsburger' the DI was $48 \%$. This suggested that disease development progressed more slowly, and was not as severe, in 'Wilhelmsburger.' These results are consistent with the previously reported reactions of these hosts to P. brassicae pathotype 3A [11]. As expected, the susceptible check, Chinese cabbage 'Granaat,' developed severe clubroot (DI $=100 \%$ at 45 dai).

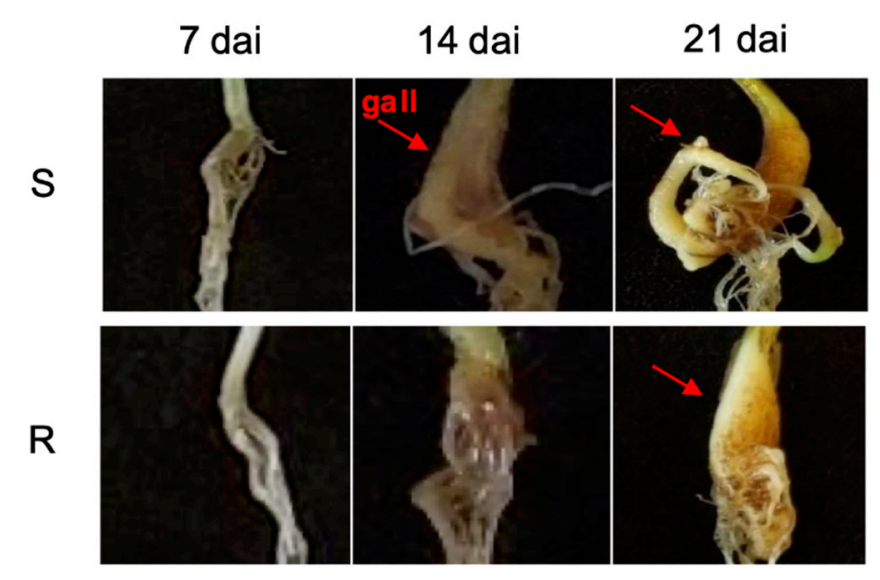

Figure 1. Phenotypes of Plasmodiophora brassicae-inoculated roots of the rutabagas 'Wilhelmsburger' (R) and 'Laurentian' (S) at 7, 14, and 21 days after inoculation (dai). A red arrow indicates the presence of galls.

\subsection{RNA-Seq Analysis}

RNA sequencing (RNA-Seq) was used to assess transcriptional changes between control and inoculated plants at 7, 14, and 21 dai. On average, 38 million reads were generated from 36 cDNA libraries. From these reads, $82.14-90.76 \%$ were aligned to the reference genome of $B$. napus. Principal component analysis (PCA) showed consistency among replicates and good separation between inoculated and non-inoculated samples (Supplementary Figure S1).

In total, 110,069 transcripts were identified across samples, which were annotated based on similarity to B. napus and Arabidopsis genes. Among these, 20,466 transcripts showed significant expression changes in at least one of six comparison sets of inoculated vs. non-inoculated samples (Supplementary Table S1). Thousands of transcripts were significantly differentially expressed at each 
time-point. At 7 dai, when no disease symptoms were yet visible in either host, more genes were significantly regulated in 'Wilhelmsburger' (3893) than 'Laurentian' (2863). At that same time-point, more upregulated genes than downregulated genes were identified in both hosts (Figure 2A). Similarly, when challenging two $B$. napus hosts with $P$. brassicae pathotype $5 \mathrm{X}$, more genes were significantly regulated in the resistant host than in the susceptible host at 7 dai [31]. At 14 dai, although fewer genes were significantly regulated in 'Wilhelmsburger' (2136) than 'Laurentian' (5717), the patterns of regulation were different in the two hosts. Around two-thirds of the genes were upregulated in the former, but more than half were downregulated in the latter (Figure 2A). At 21 dai, more significantly regulated genes were identified in 'Laurentian' $(14,519)$ than 'Wilhelmsburger' $(7391)$, with more downregulated genes than upregulated genes in both hosts (Figure 2A). A similar trend was reported by Galindo-González et al. (2020) in susceptible and resistant hosts at 21 dai [31]. In addition, 298, 25, and 16 transcripts showed opposite patterns of regulation in the two hosts at 7, 14, and 21 dai, respectively (Figure 2B-D). These genes could be key regulators of responses associated with clubroot resistance or susceptibility. The potential relevance of some of these genes in the differential host responses is discussed below.

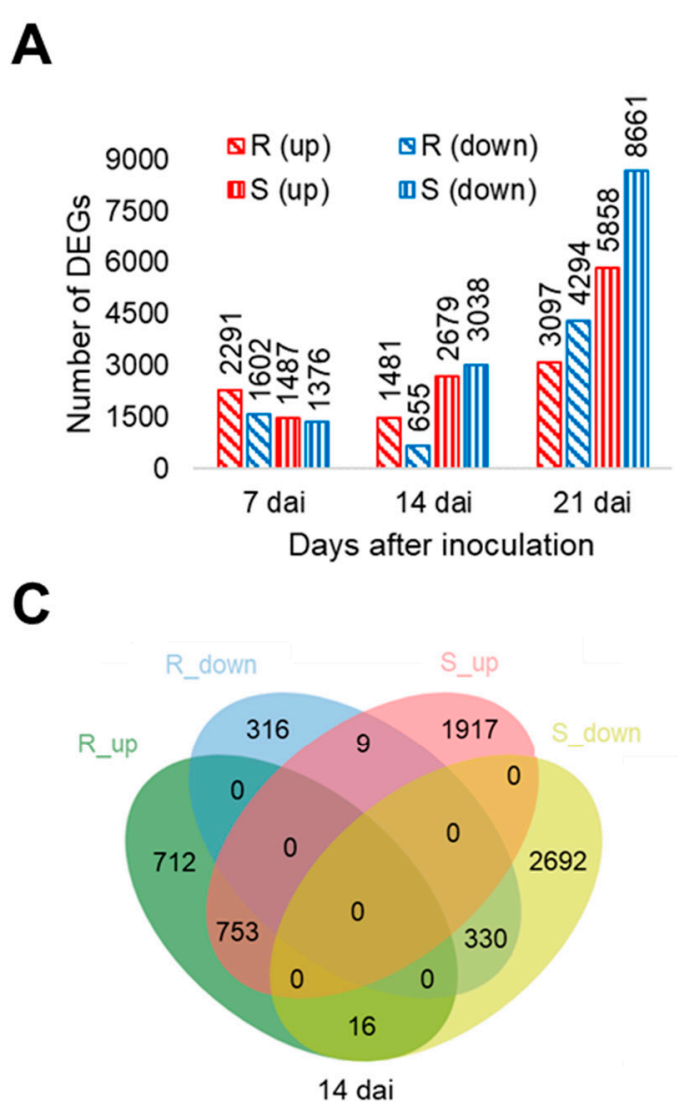

B

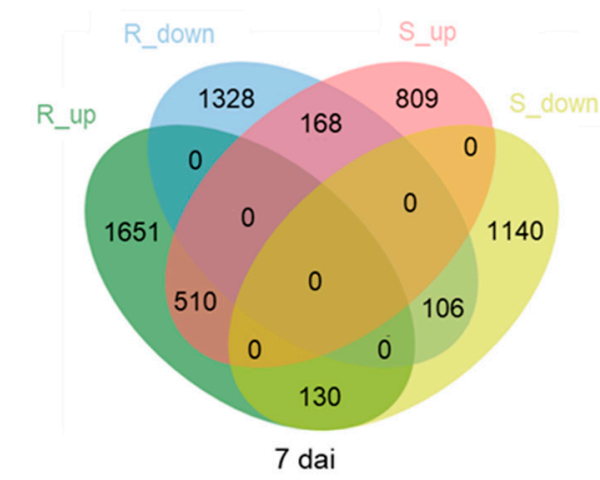

D

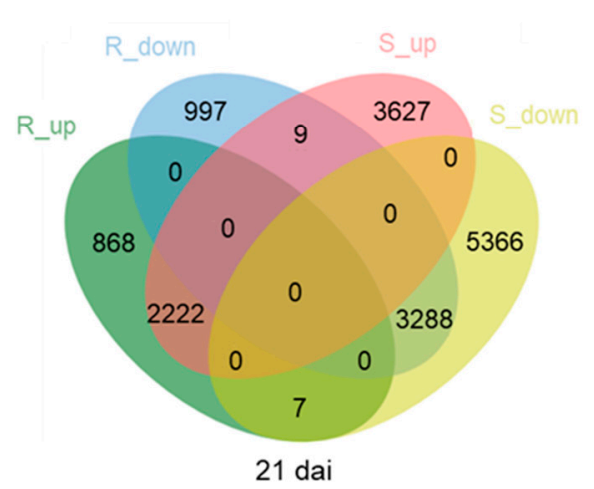

Figure 2. Number of differentially expressed transcripts in each rutabaga cultivar and time-point. (A) Number of total differentially expressed transcripts in each cultivar and time-point. (B-D) Venn diagrams showing the number of transcripts with common and unique expression patterns in the two cultivars at 7 (B), 14 (C) and 21 (D) days after inoculation (dai). Up, upregulation; down, downregulation; $\mathrm{R}$, the resistant cultivar 'Wilhelmsburger'; $\mathrm{S}$, the susceptible cultivar 'Laurentian'.

\subsection{Validation of RNA-Seq Data by Quantitative Real-Time PCR (qRT-PCR)}

The expression of 10 target genes from each cultivar at each time-point ( $P$. brassicae inoculated samples vs. non-inoculated samples) was evaluated by qRT-PCR analysis to validate the RNA-seq results. The resulting absolute $\log _{2}$ fold-change $\left(\log _{2} \mathrm{FC}\right)$ from RNA-seq and qRT-PCR indicated a high correlation among the selected genes (Figure 3). 
A

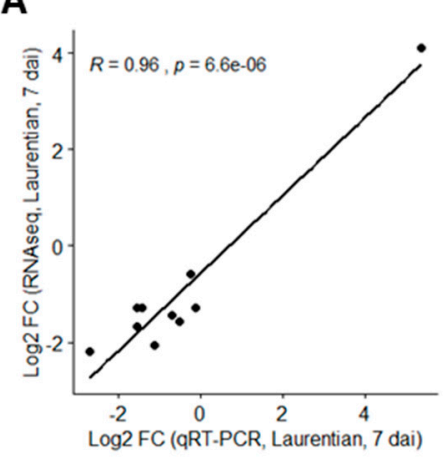

D

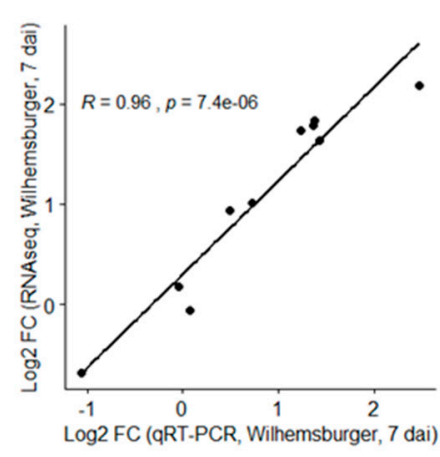

B

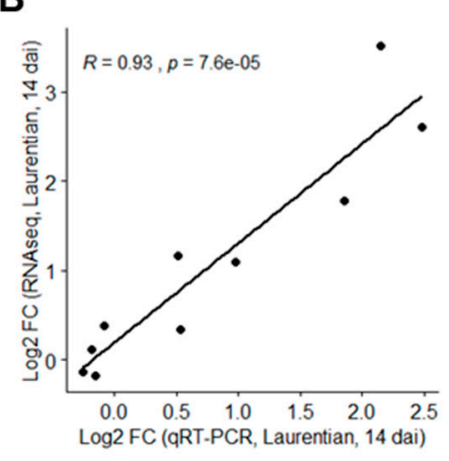

E

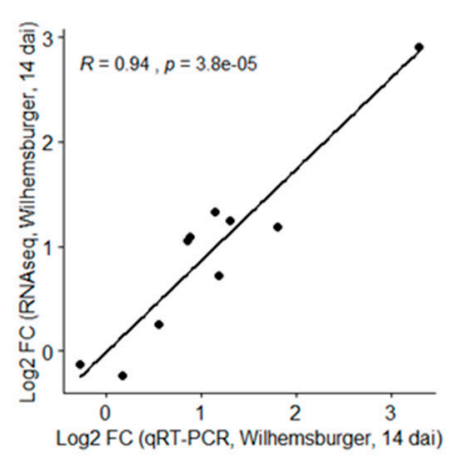

C

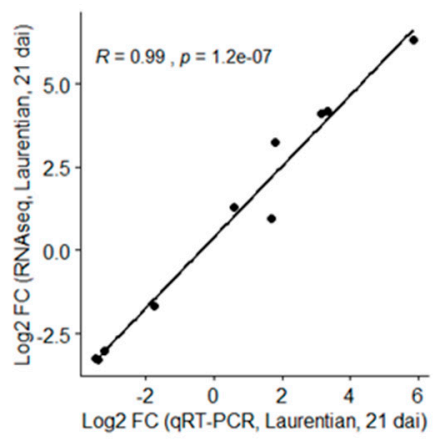

$\mathbf{F}$

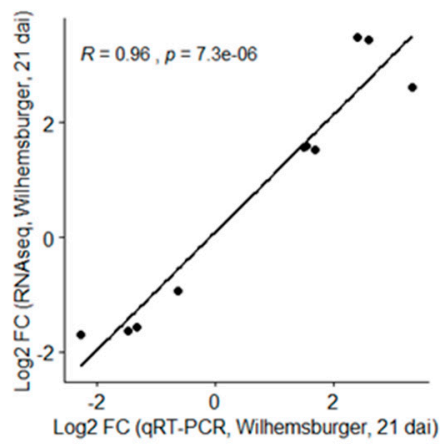

Figure 3. Correlation of $\log _{2}$ (fold-change) values of 10 selected genes based on RNA-seq and qRT-PCR analyses (inoculated versus non-inoculated). The $\mathrm{R}$ values indicate the correlation coefficient between the two methods in each host and time-point, and the $p$-values indicate the significance level of the $t$-test. (A) 'Laurentian,' 7 dai; (B) 'Laurentian,' 14 dai; (C) 'Laurentian,' 21 dai; (D) 'Wilhelmsburger,' 7 dai; (E) 'Wilhelmsburger,' 14 dai; (F) 'Wilhelmsburger,' 21 dai.

\subsection{Genes Related to Biotic Stress Pathways}

\subsubsection{Overview of Biotic Stress-Related Pathways}

Regulation of various biotic stress-associated responses is important for the host defense against $P$. brassicae infection $[26,32,33]$. Therefore, we further investigated DEGs related to biotic stress using MapMan [34], to visualize the regulation of genes in major pathways and processes related to this functional category (Figures 4 and 5 and Figure S2).

At 7 dai, more DEGs assigned to biotic stress were identified in 'Wilhelmsburger' than in 'Laurentian' (Figure 4). Among the categories designated in MapMan for biotic stress, most DEGs annotated as WRKY TFs were upregulated in both hosts. In 'Wilhelmsburger,' most of the DEGs in the ET category were upregulated, while these were mostly downregulated in 'Laurentian.' Although fewer jasmonic acid (JA)-related DEGs were identified in 'Laurentian' than in 'Wilhelmsburger,' all DEGs in 'Laurentian' were upregulated, while most genes in 'Wilhelmsburger' were downregulated. At 14 dai, while fewer DEGs in 'Wilhelmsburger' than in 'Laurentian' were assigned to biotic stress, most were upregulated (Figure 5). The largest number of DEGs assigned to various biotic stress related categories were identified in both cultivars at 21 dai; most of these genes were downregulated, with few evident differences between cultivars (Figure S2). Collectively, the results suggest that the host DEGs related to biotic stress identified at 7 and 14 dai showed a clearer distinction in their response to clubroot, than genes regulated at 21 dai. Therefore, we further analyzed DEGs involved in some major categories related to biotic stress and concentrated on differences at 7 and 14 dai (Figure 6). 

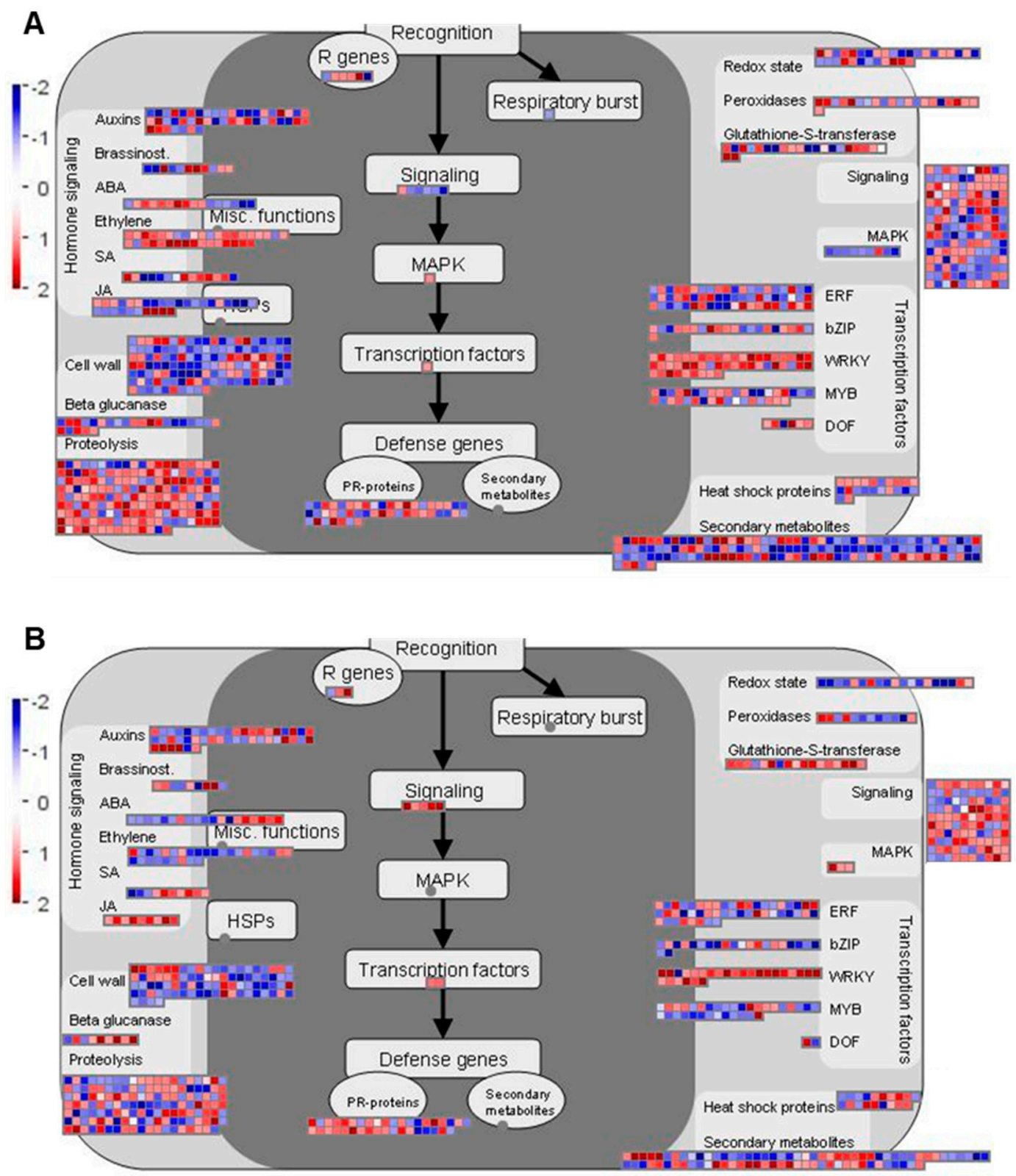

Figure 4. Distribution of differentially expressed genes involved in the biotic stress response in two rutabaga hosts at 7 days after inoculation with Plasmodiophora brassicae. (A) 'Wilhemsburger' and (B) 'Laurentian.' The $\log _{2}$ fold-changes are presented on a scale where red represents upregulation and blue represents downregulation. ABA, abscisic acid; JA, jasmonic acid; SA, salicylic acid; bZIP, basic region-leucine zipper; ERF, APETALA2/Ethylene-responsive element binding protein family; WRKY, WRKY transcription factor; MYB, MYB transcription factor; DOF, DNA-binding one zinc finger transcription factor; MAPK, mitogen-activated protein kinase; PR-protein, pathogenesis-related protein; $\mathrm{R}$ genes, resistance genes.

\subsubsection{Genes Related to SA, ET, and JA Metabolism}

Salicylic acid, JA, and ET are important pathogen-responsive plant hormones. In general, a dichotomy has been established for SA vs. JA/ET in response to biotrophic and necrotrophic pathogens, respectively [35]. This dichotomy is not always clear cut, however, and JA- or ET-related genes have been suggested to be involved in resistance responses to some biotrophic pathogens, including P. brassicae, Plasmopara viticola and Botryosphaeria dothidea [36-39]. In Arabidopsis, genes involved in both the SA and ET pathways were upregulated at 7 dai during a partially resistant response to 
P. brassicae, while genes involved in the JA pathways were downregulated [39]. A clubroot resistant inbred line of Chinese cabbage (B. rapa) carrying the $C R d$ gene activated genes related to the JA, ET, and SA signaling pathways after challenge with an avirulent $P$. brassicae pathotype, which was suggested by the authors to reflect a more potent activation of ETI [37].
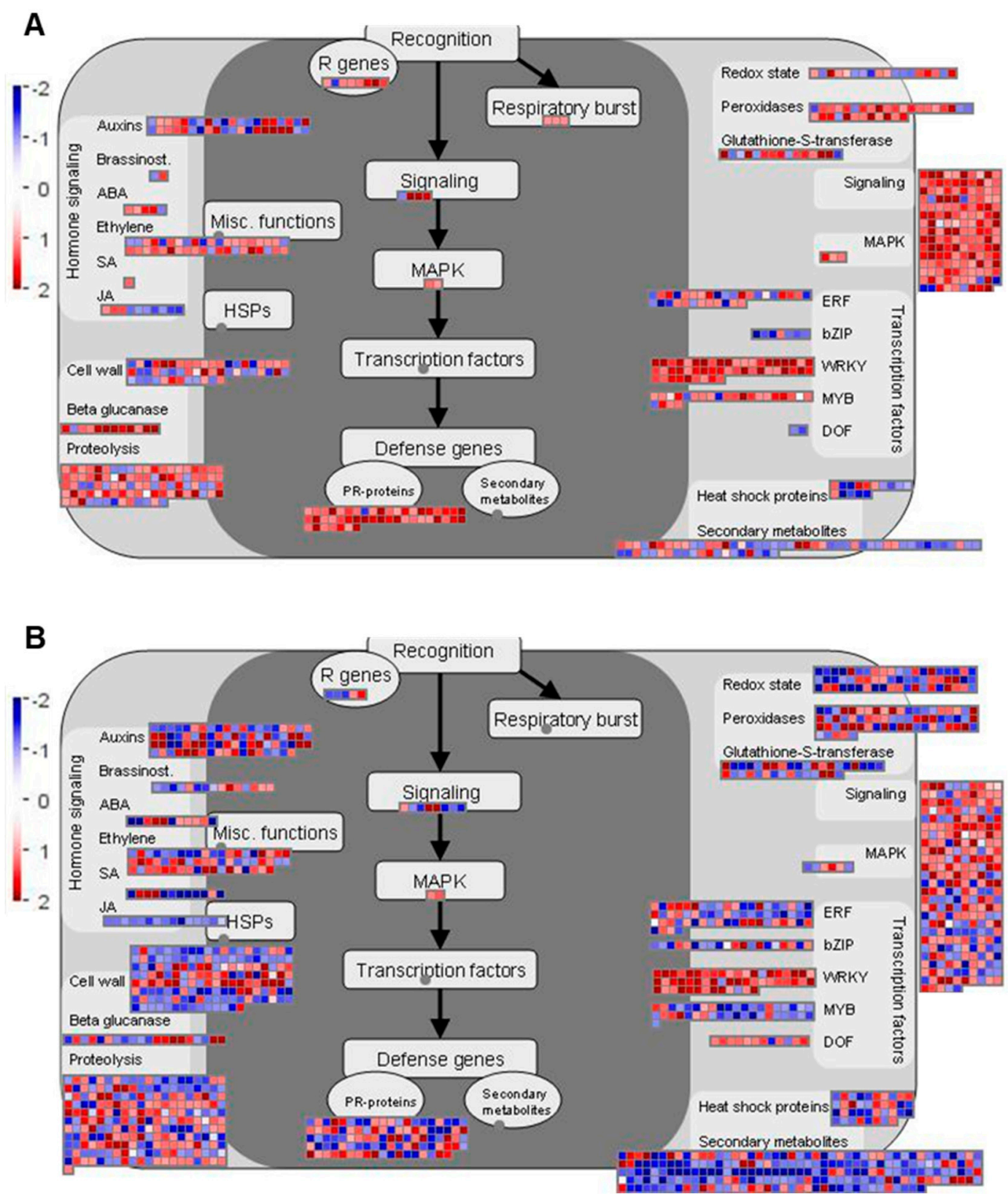

Figure 5. Distribution of differentially expressed genes involved in the biotic stress response in two rutabaga hosts at 14 days after inoculation with Plasmodiophora brassicae. (A) 'Wilhemsburger' and (B) 'Laurentian.' The $\log _{2}$ fold-changes are presented on a scale where red represents upregulation and blue represents downregulation. ABA, abscisic acid; JA, jasmonic acid; SA, salicylic acid; bZIP, basic region-leucine zipper; ERF, APETALA2/Ethylene-responsive element binding protein family; WRKY, WRKY transcription factor; MYB, MYB transcription factor; DOF, DNA-binding one zinc finger transcription factor; MAPK, mitogen-activated protein kinase; PR-protein, pathogenesis-related protein; $\mathrm{R}$ genes, resistance genes. 

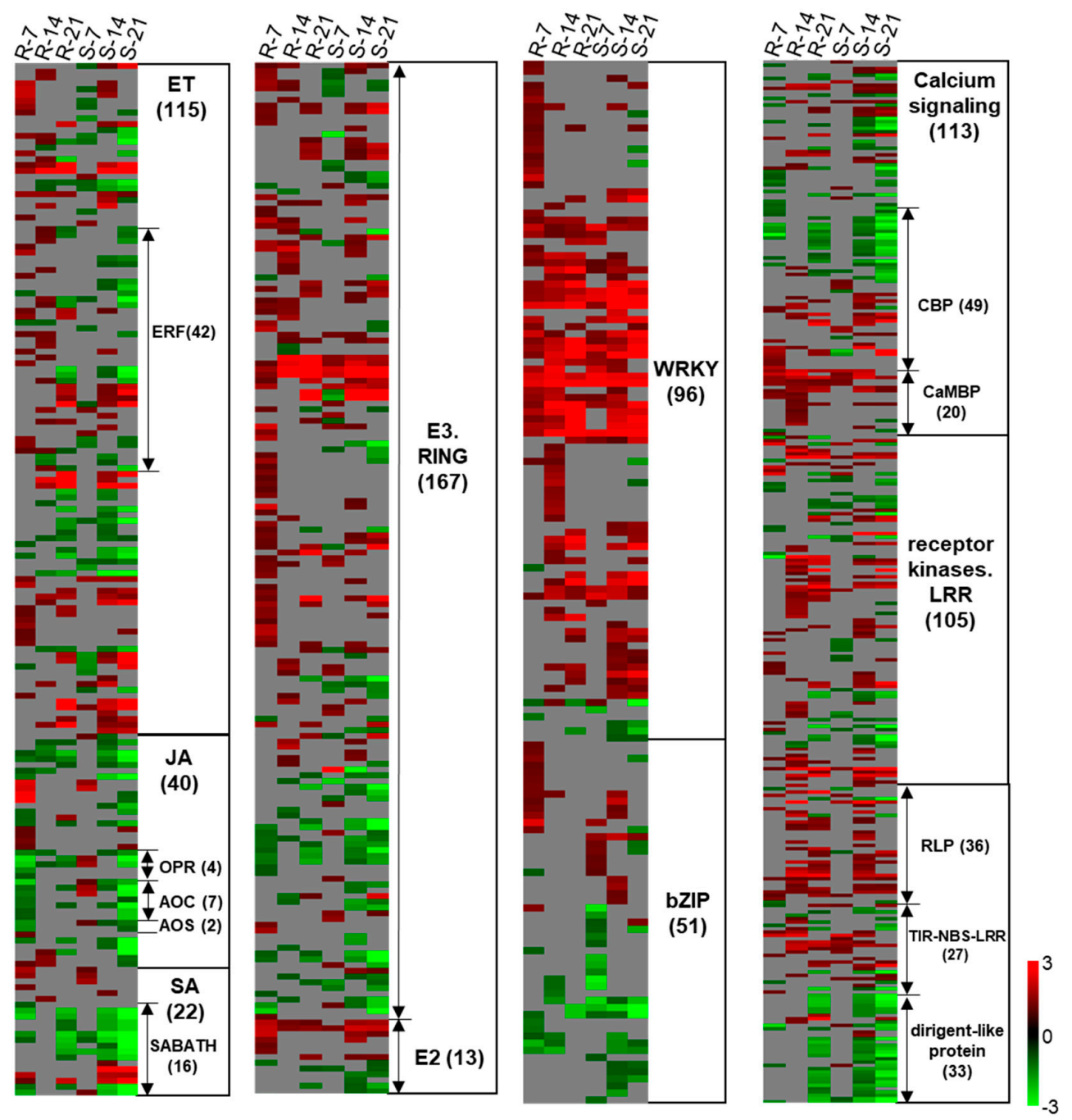

Figure 6. Heatmaps of differentially expressed genes in the resistant (R) rutabaga 'Wilhelmsburger' and the susceptible (S) 'Laurentian' in response to Plasmodiophora brassicae through the time course. Only genes that showed significant differential expression in each host at 7 or 14 dai were selected. In the heatmap scale used in this diagram, red indicates upregulation, green indicates downregulation, and gray indicates no significant regulation. ERF, ethylene response factor; JA, jasmonic acid; OPR, oxophytodienoate reductase; AOC, allene oxide cyclase; AOS, allene oxide synthase; SA, salicylic acid; SABATH, SABATH methyltransferase gene family; CBP, calcium binding protein; CaMBP, calmodulin-binding protein; LRR, leucine-rich repeat; RLP, receptor like protein. The number of transcripts for each term are indicated in parentheses.

The activation of genes involved in SA-mediated pathways has been reported widely in resistant reactions following P. brassicae inoculation [31,37,40,41]. Isochorismate synthase 1 (ICS1) and ICS2 are two genes redundantly involved in SA synthesis [42]. In our study, two transcripts corresponding to ICS1 (BnaA07g22090D and BnaC06g22820D) were upregulated in both 'Wilhelmsburger' and 'Laurentian' across the three time-points; one transcript corresponding to gene ICS2 (BnaC08g18420D) was upregulated in both hosts at 7 and 14 dai (Supplementary Table S1). The marker gene for SA-mediated responses, pathogenesis-related gene 1 (PR1, BnaC03g45470D), showed high upregulation in both 'Laurentian' and 'Wilhelmsburger' over time, with the exception of no significant regulation in 'Laurentian' at 7 dai $\left(\log _{2} \mathrm{FC}=2.6, q\right.$ value $\left.>0.05\right)$ (Supplementary Table S1). Upregulation of these genes suggests the involvement of SA-triggered immunity in both hosts. The same ICS2 and PR1 genes were also upregulated in 'Laurentian' at 7, 14, and 21 dai, when it was challenged with P. brassicae pathotype 5X [31]. In both hosts, most genes related to SA metabolism corresponded 
to downregulated transcripts belonging to the SABATH methyltransferase gene family (Figure 6). Members of this family are important for the methylation of phytohormones [43], which can inactivate SA by converting it to methyl salicylate [44]. At 7 dai, three of four transcripts belonging to the SABATH methyltransferase gene family were downregulated in 'Laurentian,' and seven of nine transcripts of the same family were downregulated in 'Wilhelmsburger,' including one that was upregulated in 'Laurentian' (BSMT1, BnaA03g31730D) (Figure 6 and Supplementary Table S2). The clubroot pathogen can manipulate host SA levels to weaken host defenses, by secreting methyltransferase PbBSMT, which leads to strong conversion of SA to methyl salicylate at infection sites; overexpression of BSMT1 in Arabidopsis reduced SA levels by half, although this manipulation alone did not alter susceptibility to P. brassicae [45]. Our results suggest stronger repression of SA methylation in 'Wilhelmsburger' than in 'Laurentian' at 7 dai, but a SA-mediated response is likely involved in both cultivars.

Ethylene-mediated responses are part of clubroot defense mechanisms in plants with various backgrounds. For example, genes related to signaling and ET metabolism were upregulated in resistant plants carrying the CR gene Rcr1 relative to susceptible plants that lacked this gene [46]. Similarly, in a Chinese cabbage inbred line carrying a CR gene $C R d$, ET signaling-related genes were upregulated when challenged with an avirulent pathotype of P. brassicae, but were not regulated when challenged with a virulent pathotype [37]. Several Arabidopsis mutants of genes within the ET signaling pathway showed increased susceptibility to $P$. brassicae infection [47]. In our study, regulation of genes involved in the ET category showed the greatest differences between the two cultivars at 7 dai, as 33 of 38 transcripts in 'Wilhelmsburger' were upregulated and 23 of 30 significantly regulated transcripts in 'Laurentian' were downregulated (Figure 6 and Supplementary Table S2). Ethylene response factors (ERFs) are important in activating other defense genes in response to P. brassicae [47]. In our study, 'Wilhelmsburger' had more upregulated transcripts annotated as ERFs (11) than 'Laurentian' (2) at 7 dai, a trend that was also observed at 14 dai (Figure 6). For example, at 7 dai, three transcripts corresponding to the ethylene response factor 104 (ERF104) were upregulated in 'Wilhelmsburger,' and two of those transcripts were downregulated in 'Laurentian' (BnaC07g31350D and BnaA03g40380D). ERF104 is activated by MAP kinase 6 (MPK6) upon perception of bacterial flagellin peptide flg22 in Arabidopsis, which alters plant susceptibility to Pseudomonas syringae [48]. A transcript matching the gene MPK6 (BnaC03g24500D) was activated only in 'Wilhelmsburger' but not in 'Laurentian' at 7 dai (Supplementary Table S1), suggesting that upregulation of ERF104 and MPK6 may be involved in clubroot resistance. In addition, three transcripts matching ERF11 were upregulated in 'Wilhelmsburger' and not in 'Laurentian' at 7 and/or 14 dai (Table S2). Similarly, overexpression of ERF11 in apple increased its resistance to the biotrophic fungus $B$. dothidea by enhancing accumulation of SA and expression of SA synthesis-related and signaling-related genes [36], suggesting possible cross-talk between ET and SA in some biotrophic interactions.

Jasmonic acid-related genes also showed the greatest differences in expression at 7 dai, when 22 of 31 DEGs in 'Wilhelmsburger' were downregulated and all nine DEGs in 'Laurentian' were upregulated (Figure 6). Six transcripts involved in JA biosynthesis, including 12-oxophytodienoate reductase 1 (OPR1, BnaC09g41020D and BnaA10g17650D), allene oxide cyclase 2 (AOC2, BnaA06g33410D, BnaC09g52570D, and BnaA09g19550D), and allene oxide synthase (AOS, BnaA02g23180D), were downregulated in 'Wilhelmsburger' and upregulated in 'Laurentian' (Table S2). This contrasting pattern of expression is consistent with the regulation of JA biosynthesis genes in CR and CS responses, which was reported in other studies at early stages of infection [39,49]. At 14 and 21 dai, genes in the JA category showed general downregulation in both hosts (Figure 6). Collectively, our results suggest that JA does not seem central to defense in the resistant cultivar, while it may be a mechanism that is activated in this susceptible interaction.

\subsubsection{Pathogenesis-Related (PR) Genes}

The most notable differences in regulation of $P R$ genes between 'Wilhelmsburger' and 'Laurentian' were detected at 14 dai. At this time-point, while fewer $P R$ genes were identified in the resistant 
vs. the susceptible host, most were upregulated in the former (46 of 47), while 45 of 98 genes were downregulated in the latter (Figure 5).

Transcripts encoding RLP and TIR-NBS-LRR proteins showed general upregulation in both hosts at 14 dai (Figure 6). All 19 genes encoding RLPs were upregulated in 'Wilhelmsburger,' while 20 of 21 were upregulated in 'Laurentian.' Receptor-like proteins are key components of PRRs, which recognize PAMPs or endogenous DAMPs to activate PTI-mediated responses [14]. For example, the protein RLP30 is required for perception of a fungal PAMP known as sclerotinia culture filtrate elicitor 1 (SCFE1) [50]. Another protein RLP23 binds to a conserved 20 amino acid fragment from necrosis and ethylene-inducing peptide 1-like proteins (NLPs) produced by multiple bacterial, oomycete, and fungal microbes, and mediates plant resistance to diverse pathogens such as Phytophthora infestans and Sclerotinia sclerotiorum [51]. In our study, transcripts encoding RLP23 and RLP30 were upregulated in both hosts (Supplementary Table S2), suggesting a role in basal responses to clubroot. In addition, 10 upregulated transcripts corresponding to TIR-NBS-LRR proteins were identified in 'Wilhelmsburger' and nine were identified in 'Laurentian.' Only four of these, however, were found to be commonly upregulated in the two hosts (Figure 6 and Supplementary Table S2). TIR-NBS-LRR genes are $R$ genes linked to ETI responses [13] and are important for clubroot resistance, representing one of the main sources of candidate CR genes [20,21]. We identified the gene BnaA03g29300D, which is the homolog of the CR gene, CRd (Bra001175), in B. rapa [21]. This gene was upregulated earlier in 'Wilhelmsburger' (14 dai) than in 'Laurentian' (21 dai). Another gene, BnaAnng17440D, which was upregulated in 'Wilhelmsburger' but not regulated in 'Laurentian' at 7 dai, was similar to the candidate resistance gene $C R d$ (Bra001160) [21], based on our sequence alignment analysis. Resistance associated with CRd is related to the activation of genes involved in both SA and ET signaling pathways [37], which is consistent with the upregulation of genes related to these hormones in this study.

In addition, $P R$ genes involved in SA-mediated defense also showed differential regulation between the two hosts at 7 dai, including $P R 1$, which was only upregulated in 'Wilhelmsburger,' and the nonexpresser of $P R$ genes 1 (NPR1)-like protein 3 (NPR3), which was upregulated only in 'Laurentian' (Supplementary Table S1). The upregulation of $P R 1$ in clubroot resistance responses has been reported widely $[24,25,37]$. $P R 1$ is a marker gene for SA-mediated resistance, which is positively regulated by TGACG motif-binding protein (TGA) and NPR1 genes [52]. In contrast, NPR3 is a co-repressor of SA-induced defense gene expression; it interacts with TGAs to inhibit expression of defense-related genes under low SA levels, while its repression is inhibited when SA is high [53].

Expression of transcripts belonging to the dirigent-like protein family was most divergent between 'Laurentian' and 'Wilhelmsburger' at 14 dai. Twenty-seven of these transcripts were downregulated in 'Laurentian' at this time, while two were upregulated in 'Wilhelmsburger' (Figure 6). Genes belonging to this family are thought to participate in biotic and abiotic defense by increasing lignan and lignin synthesis [54]. Lignin synthesis positively regulates clubroot resistance $[55,56]$. Our results showed that, at 14 dai, more genes involved in lignin biosynthesis were downregulated in 'Laurentian' (23 of 26 genes) than in 'Wilhelmsburger' (four of eight genes) (Supplementary Figure S3). At this time-point, two transcripts matching genes encoding dirigent protein 6 (DIR6, BnaAnng27090D and BnaC01g15510D) were downregulated in 'Laurentian,' but were not regulated in 'Wilhelmsburger.' These genes contain the TIR-NBS-LRR domain, and their sequences showed high similarity to Bo7g109000 in B. oleracea, a gene that is located in the target region of a major clubroot resistance gene Rcr7 [57]. This indicates that greater downregulation of genes in the dirigent-like protein family in 'Laurentian' may be associated with more rapid galling of the roots.

\subsubsection{Signaling}

Signaling networks are important for the activation of plant defenses against clubroot [33]. As with the $P R$ genes, genes involved in signaling pathways showed notable differences in expression at 14 dai, with a greater proportion of these genes upregulated in 'Wilhelmsburger' vs. 'Laurentian' (Figure 5). This was especially evident for calcium regulated genes and LRR receptor kinases (Figure 6). A transcript 
encoding the LRR receptor kinase pep 1 receptor 2 (PEPR2, BnaC05g49970D) was upregulated in 'Wilhelmsburger' at 7 dai but downregulated in 'Laurentian' at 7 and 14 dai (Supplementary Table S2). The protein PEPR2 perceives Arabidopsis DAMP Pep1/2 peptide, and cooperates with ET to amplify resistance to Botrytis cinerea $[58,59]$. In addition, three transcripts encoding a protein suppressor of BIR1-1 (SOBIR1) were upregulated in 'Wilhelmsburger' at 14 dai, of which only one was upregulated in 'Laurentian.' The protein SOBIR1 interacts with various RLPs, such as RLP23 and RLP30 (discussed above), to enhance plant immunity upon fungal pathogen challenge [50,51,60].

In the calcium signaling subcategory, most upregulated transcripts in 'Wilhelmsburger' at 14 dai encoded calcium binding proteins (CBPs; all eight transcripts upregulated) and calmodulin-binding proteins (CaMBPs; all 17 transcripts upregulated). At the same time-point, a large portion of $C B P$ transcripts (14 of 26) was downregulated in 'Laurentian,' and only seven transcripts encoding CaMBPs were upregulated in this cultivar (Figure 6). This is consistent with previous transcriptomics studies suggesting a $\mathrm{Ca}^{2+}$ influx in the clubroot resistance response $[24,25]$. Several members of the CaMBP family are important in plant defense. For example, CaMBP 60-like G (CBP60g) and the closely related SAR deficient 1 (SARD1) gene are involved in SA biosynthesis and pathogen defense responses [44]. These two genes showed upregulation in the resistant interaction at 14 dai when challenged with P. brassicae pathotype 5X [31]. Our results showed that at 14 dai, all three transcripts matching CBP60g were upregulated only in 'Wilhelmsburger.' At that same time, five transcripts annotated as SARD1 were also upregulated in 'Wilhelmsburger,' of which three were upregulated in 'Laurentian' (Supplementary Table S2). $\mathrm{Ca}^{2+}$ also activates burst oxidase homolog $(\mathrm{RBOH})$ proteins, which are key factors in enhancing production of ROS during the plant immunity response [61]. This type of response has been well studied in clubroot interactions $[24,33,41,49,62,63]$. In our analysis, three transcripts annotated as $\mathrm{RBOHs}(\mathrm{RBOHA}, \mathrm{RBOHC}$, and $\mathrm{RBOHG}$ ) were upregulated in 'Wilhelmsburger' but not in 'Laurentian' at 14 dai (Supplementary Table S1). The homologs of the same three genes were upregulated in clubroot resistant wild cabbage (B. macrocarpa) following P. brassicae infection [62]. Collectively, our results support activation of genes involved in calcium-dependent defense responses against clubroot.

\subsubsection{Transcription Factors}

Transcription factors play important roles in modulating the host immune responses [64]. The activation of WRKY TFs in plants in response to $P$. brassicae has been reported widely $[24,25,37,39,41,63]$. In the present study, most WRKY TFs were upregulated in both hosts over the entire time-course (Figures 4 and 5 and Supplementary Figure S2). Some transcripts were upregulated in 'Wilhelmsburger' but not regulated in 'Laurentian' at 7 or 14 dai, including WRKY22, WRKY29, WRKY33, and WRKY46 at 7 dai, and WRKY46 and WRKY53 at 14 dai. WRKY46, WRKY53, and $W R K Y 70$ are involved in the SA-signaling pathway and play overlapping and synergistic roles in plant resistance to P. syringae [65]. In our study, at least five transcripts annotated as WRKY70 genes were upregulated in both hosts at all three time-points, except in 'Laurentian' at 7 dai (three genes). These results suggest that the activation of WRKY46, WRKY53, and WRKY70 is associated with SA-mediated defense responses to clubroot, and that regulation of WRKY46 and WRKY70 at 7 dai may be related to enhanced SA-mediated responses in 'Wilhelmsburger.' WRKY22 and WRKY29 are activated in PTI and regulate resistance to P. syringae and B. cinerea [66]. While WRKY33 typically has been associated with resistance to necrotrophic fungal pathogens [67], its upregulation in response to $P$. brassicae has also been reported and is believed to be modulated by MPK6 [25,41,63]. In our study, a transcript matching MPK6 and another matching the ET synthesis gene 1-amino-cyclopropane-1-carboxylate synthase 2 (ACS2), which is activated by MPK6-WKRY33 [68], exhibited an expression pattern similar to WRKY33 in both 'Wilhelmsburger' and 'Laurentian' at 7 dai (Supplementary Table S2). This suggests that MPK6-WKRY33 may contribute to ET synthesis to enhance clubroot resistance. In addition to WRKY33, WRKY22, WRKY29, and WRKY46 are also activated by MPK6 following pathogen challenge $[66,68,69]$. For example, in cabbage showing resistance to $P$. brassicae, the activation 
of MEKK1-MKK4/MKK5-MPK3/MPK6 resulted in upregulation of WRKY22/WRKY29/WRKY33 [63]. Collectively, these results indicate a central role of $W R K Y_{S}$ in regulatory defense responses to clubroot.

Members of the basic leucine zipper (bZIP) TF family are important regulators of many key developmental and physiological processes, including biotic stress responses [70]. The upregulation of some $b Z I P s$ has been associated with CR responses [39,41]. TGAs, a type of $b Z I P$ TF, are important for activating SA-regulated genes such as PR1 [52]. In our study, 'Wilhelmsburger' showed a higher proportion of upregulated $b$ ZIP TFs than 'Laurentian' at 7 dai (Figure 6). Three transcripts annotated as TGA10 and five encoding TGA1 were upregulated only in 'Wilhelmsburger' at 7 dai (Supplementary Table S2), which may be associated with the upregulation of $P R 1$ observed in this host.

\subsubsection{Protein Degradation}

Proteolysis-related genes also showed distinct differences in expression between 'Laurentian' and 'Wilhelmsburger.' While numerous genes involved in protein degradation were regulated in both hosts, proportionally more genes were upregulated in 'Wilhelmsburger' and downregulated in 'Laurentian' at 7 and 14 dai (Figures 5 and 6). At 7 dai, five transcripts encoding E2 ubiquitin-conjugating enzymes (E2) and 57 transcripts encoding E3 ubiquitin ligase (E3) RING proteins were upregulated only in 'Wilhelmsburger' (Figure 6), of which two WAV3 homolog 1 (WAVH1) genes (BnaC04g35190D and BnaA04g13100D) and two BCA2Â zinc finger ATL 10 (BTL10) genes (BnaA06g17960D and BnaCnng37520D) were downregulated in 'Laurentian' (Supplementary Table S2). At 14 dai, proportionally more transcripts encoding E2 and E3 RING proteins were upregulated in 'Wilhelmsburger' (38 of 50 transcripts) than in 'Laurentian' (49 of 82 transcripts) (Figure 6). The E2 ubiquitin-conjugating enzymes and E3 ubiquitin ligase proteins are key components of the ubiquitin-proteasome system. These enzymes bind to ubiquitin and form multimers that attach to proteins, targeting them for degradation by $26 \mathrm{~S}$ proteasomes. This ubiquitin-proteasome system interacts with key components of plant immunity to positively or negatively regulate resistance to plant pathogens [71]. Genes encoding RING proteins in the E3 ubiquitin pathway were upregulated in Rcr1-mediated clubroot resistance and downregulated in susceptible Arabidopsis following P. brassicae infection [32,72]. Several genes in the Arabidopsis Tóxicos en Levadura (ATL) family encoding E3 RING proteins are involved in plant defense against pathogens [71]. In our study, two transcripts matching ATL2 and three transcripts matching ATL31 were upregulated in 'Wilhelmsburger' at both 7 and 14 dai, of which one of each were also upregulated in 'Laurentian' at 14 dai. (Supplementary Table S2). ATL2 and ATL31 are induced by pathogens or PAMPs [73]. The expression of PR1 was induced in Arabidopsis mutants constitutively expressing ATL2 [74]. Overexpression of ATL31 in Arabidopsis increased resistance to $P$. syringae, while knock-out of these genes decreased resistance [75]. One of our ATL31 genes (BnaA09g03720D) was upregulated in the resistant 'Laurentian' but downregulated in susceptible 'Brutor' (B. napus) when inoculated with P. brassicae pathotype 5X [31], suggesting that SA levels may increase in the resistant interaction.

\subsection{Analysis of Genes with Opposite Regulation in the Resistant vs. Susceptible Hosts}

We identified many genes with opposite patterns of regulation in the two hosts at each of 7, 14, and 21 dai (Figure 2B-D), and discussed some of these genes in the Section 2.4. Here, we further investigated their expression and putative functions to select good candidates for gene editing-based functional validation.

We first divided genes identified at 7 dai into two lists: genes upregulated in 'Wilhelmsburger' but downregulated in 'Laurentian' (List A and Supplementary Table S3a) and genes downregulated in 'Wilhelmsburger' but upregulated in 'Laurentian' (List B and Supplementary Table S3b). Genes on each list were then grouped based their functional categories in Mapman [34]. The majority of genes on both lists (33.6\% in List A and $27.3 \%$ in List B) belonged to the "not assigned" category (i.e., did not match any Mapman classification), followed by "RNA" (23\% in List A and 12.7\% in List B) and "hormone metabolism" (10.7\% in List A and $11.3 \%$ in List B) (Figure 7A,B). These results supported the 
importance of transcriptional regulation and hormone metabolism in the B. napus-P. brassicae interaction at 7 dai. The functional category "lipid metabolism" was identified only on List B (6.7\%). Five of 10 transcripts involved in lipid metabolism were related to lipid synthesis (Supplementary Table S3b), which is consistent with the upregulation of lipid synthesis genes in P. brassicae-infected roots and the accumulation of lipid droplets in the parasite as a nutrient sink for P. brassicae survival [76,77]. In addition, JA is a lipid-derived signal $[78,79]$, consistent with the similar regulation patterns of JA and lipid synthesis related genes in this study. A transcript matching gene fatty acid desaturase 7 (FAD7, BnaA03g31600D) was downregulated in 'Wilhelmsburger' $\left(\log _{2} \mathrm{FC}=-1.21\right)$ and upregulated in 'Laurentian' $\left(\log _{2} \mathrm{FC}=1.02\right)$. Fatty acid desaturase $7(F A D 7)$ is involved in the synthesis of both fatty acid and JA, but it inhibits SA accumulation and signaling [80], suggesting that this gene could be an important candidate susceptibility factor.

A

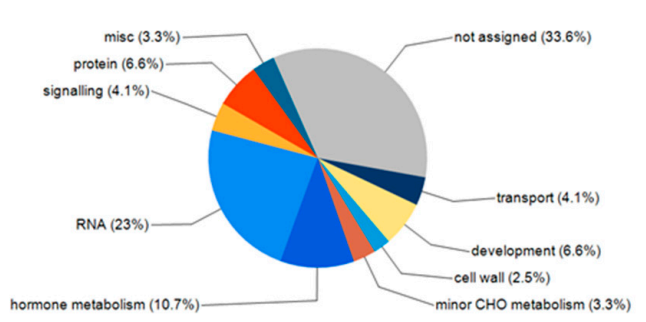

B

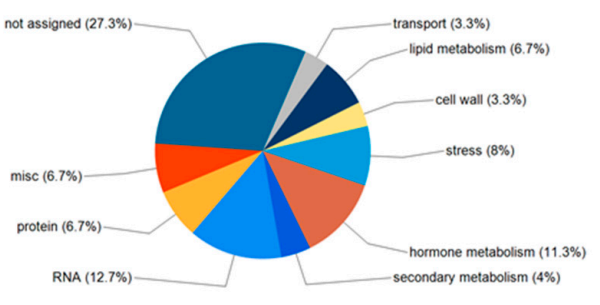

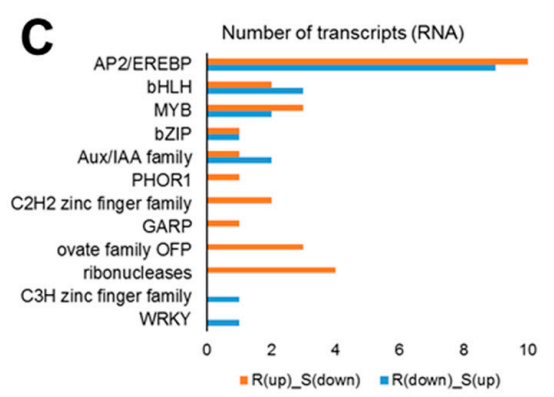

Figure 7. Distribution of the number of transcripts showing opposite regulation patterns in the resistant (R) rutabaga 'Wilhelmsburger' and the susceptible (S) 'Laurentian' at 7 days after inoculation with Plasmodiophora brassicae, using Mapman annotation. (A) Pie chart generated from transcripts upregulated in 'Wilhlemsburger' and downregulated in 'Laurentian.' (B) Pie chart generated from transcripts downregulated in 'Wilhelmsburger' and upregulated in 'Laurentian.' (C) Number of transcripts related to RNA regulation.

Most transcripts assigned to the "RNA" functional category matched the APETALA2 (AP2)/ethylene-responsive element binding protein (EREBP) (10 on List A and 9 on List B) (Figure 7C). Members of the ERF subfamily of AP2 TFs are involved in the regulation of disease resistance pathways, and some ERFs have been shown to be regulated by plant hormones (ET, JA, and SA) and pathogen challenge [81]. The high proportion of additional regulated ERFs in the AP2/EREBP gene family in 'Wilhelmsburger' and 'Laurentian' at 7 dai (Supplementary Tables S3a,b) supports the importance of ERFs in the host response to P. brassicae. However, ERFs may play different roles in resistant and susceptible interactions, since they are distributed on both List A and List B. In addition, two of the transcripts on List A matched a TF MYB15, which is consistent with upregulation of this gene in a CR rapeseed accession but not in a CS accession upon P. brassicae infection [82]. MYB15 contributed to resistance to P. syringae in Arabidopsis [83]. In Chinese wild grape (Vitis quinquangularis), MYB15 was induced when plants were treated with flg22 and P. viticola, making its promoter a potential target for 
disease resistance breeding [84]. This suggests that MYB15 may also be a good candidate for functional validation in clubroot resistance.

On List A, the transcript showing the most distinct regulation in the two hosts at 7 dai matched the gene plastidic type I signal peptidase 2A (PLSP2A, BnaC05g04750D); this transcript showed the greatest upregulation in 'Wilhelmsburger' $\left(\log _{2} \mathrm{FC}=4.86\right)$ and the greatest downregulation in 'Laurentian' $\left(\log _{2} \mathrm{FC}=-3.52\right)$. PLSP2A corresponds to a thylakoidal processing peptidase usually expressed in both photosynthetic tissues and roots and is important for thylakoid membrane organization [85]. In cabbage (B. oleracea), a large portion of differentially modulated proteins in resistant vs. susceptible interactions with P. brassicae was localized to the thylakoid [86]. These results suggest that PLSP2A could be an important candidate for resistance to $P$. brassicae. A gene involved in phosphorylation of the thylakoid membrane has been suggested as a candidate for resistance to Leptosphaeria maculans in B. napus [87]. On list B, the two transcripts showing the greatest downregulation in 'Wilhelmsburger' matched two copies of "cytochrome P450, family 94, subfamily C, polypeptide 1" (CYP94C1, BnaC04g16670D, and BnaA07g13320D, $\left.\log _{2} \mathrm{FC}=\sim-4\right)$, both of which were upregulated in 'Laurentian' $\left(\log _{2} \mathrm{FC}=\sim 1.7\right)$. In addition, transcripts matching three copies of CYP94B1 (BnaC03g50910D, BnaA06g38770D, and BnaA09g06580D) were also identified on List B. Both CYP94C1 and CYP94B1 are induced by JA treatment and involved in the catabolism and deactivation of jasmonoyl-L-isoleucine (JA-Ile), a major bioactive form of JA [88]. Expression of CYP94C1 also increased in early galling tissues in Chinese sumac (Rhus javanica) infested by aphids (Schlechtendalia chinensis) [89]. Collectively, these findings suggest that CYP94C1 and CYP94B1 could be good candidate susceptibility factors during clubroot development.

Transcripts showing opposite regulation patterns in 'Wilhelmsburger' and 'Laurentian' at 14 dai are listed in Table S3c,d. At this time-point, the transcript showing the greatest upregulation in 'Wilhelmsburger' corresponded to an LRR transmembrane protein kinase (BnaC05g27810D) $\left(\log _{2} \mathrm{FC}=4.12\right)$, which was downregulated in 'Laurentian' $\left(\log _{2} \mathrm{FC}=-1.25\right)$. Its orthologous gene in Arabidopsis encodes a protein localized to the plasma membrane, where a large portion of upregulated gene products were identified in a clubroot resistant reaction in B. rapa [46]. Considering the possible roles of LRR protein kinases in mediating resistance to pathogens, this gene may be another candidate of resistance. A transcript matching cytochrome p450 79f1 (CYP79F1) was downregulated in 'Laurentian' $\left(\log _{2} \mathrm{FC}=-2.52\right)$ and upregulated in 'Wilhemsburger' $\left(\log _{2} \mathrm{FC}=1.15\right)$. An Arabidopsis mutant of CYP79F1 had reduced aliphatic glucosinolate and increased indole glucosinolate content [90]. Higher aliphatic glucosinolates and lower indole glucosinolates levels have been associated with clubroot resistance in previous studies [41,91]. Transcripts matching two other key genes involved in aliphatic glucosinolate synthesis (CYP83A1 and bile acid transporter 5 (BAT5)) $[92,93]$ showed a pattern of regulation similar to CYP79F1. Recently, CYP83A1 has been screened as a candidate gene for clubroot resistance in rapeseed, by combining functional enrichment analysis, co-expression network analysis, and haplotype analysis [82]. These results suggest that these aliphatic glucosinolates synthesis-related genes may be good candidates for increasing clubroot resistance.

At 21 dai, the most upregulated transcript in 'Wilhelmsburger' and the most downregulated transcript in 'Laurentian' did not match any B. napus or Arabidopsis gene annotations. A transcript matching BnaA04g25230D/AT2G43610 belonging to the chitinase family protein, however, showed the second highest level of upregulation in 'Wilhelmsburger' $\left(\log _{2} \mathrm{FC}=1.53\right)$, contrasting with downregulation in 'Laurentian' $\left(\log _{2} \mathrm{FC}=-1.53\right)$ (Supplementary Table S3e). Chitinases are a subgroup of PR proteins which attack pathogens directly by hydrolyzing chitin, a component of P. brassicae and many fungal cell walls $[94,95]$. The differential regulation of chitinase genes has been described in the defense response to $P$. brassicae $[24,56,96]$.

\subsection{A Model of the Molecular Response in the Resistant Cultivar 'Wilhemsburger' to P. brassicae}

Based on the discussion above, we propose a model of the major defense mechanisms induced by $P$. brassicae pathotype $3 \mathrm{~A}$ in its interaction with the resistant $B$. napus 'Wilhelmsburger' (Figure 8 ). Upon infection, PRRs (e.g., RLP23, RLP30, SOBIR1, PEPR2) on the host cell surface recognize 
extracellular PAMPs and DAMPs, leading to PTI. In parallel, $R$ proteins (e.g., TIR-NBS-LRR) recognize specific effectors from the pathogen, triggering ETI. The two-layer immunity of PTI and ETI have overlapping roles in the defense network, such as activating MAPKs [97]. Activated MAPKs can phosphorylate TFs to enhance their transcriptional activity [98]. For example, regulation of MPK6 resulted in the activation of multiple WRKY TFs, including WRKY22, WRKY29, WRKY33, and WRKY46, in the resistant host in our study. Furthermore, some WRKY TFs may mediate resistance by regulating plant hormone metabolism. WRKY33 activates the ET biosynthesis gene ACS2, while WRKY46, WRKY53, WKRY70, and some $b Z I P$ TFs (e.g., TGA1 and TGA10) positively regulate SA signaling. In parallel, ERF11 and ERF104 are involved in ET signaling. Our results also suggest the activation of calcium-dependent defenses, which may contribute to the activation of $R B O H s$, key genes for ROS production, and several SA synthesis genes. Infection by P. brassicae may also induce expression of RING-type ubiquitin ligase genes. In particular, ATL2 and ATL31 may play a role in defense by enhancing SA-mediated responses. The involvement of genes related to SA-mediated responses and their antagonistic effect on JA-related genes as a clubroot defense mechanism is consistent with a recent report by Galindo-González et al. (2020) [31]. Our results suggesting the importance of ET-related genes, however, contrast with the findings of Galindo-González et al. (2020) [31]. This apparent contradiction may reflect specific pathotype by host interactions, and the evaluation of multiple pathotypes with similar hosts may help to identify common defense and susceptibility genes across the clubroot pathosystem.

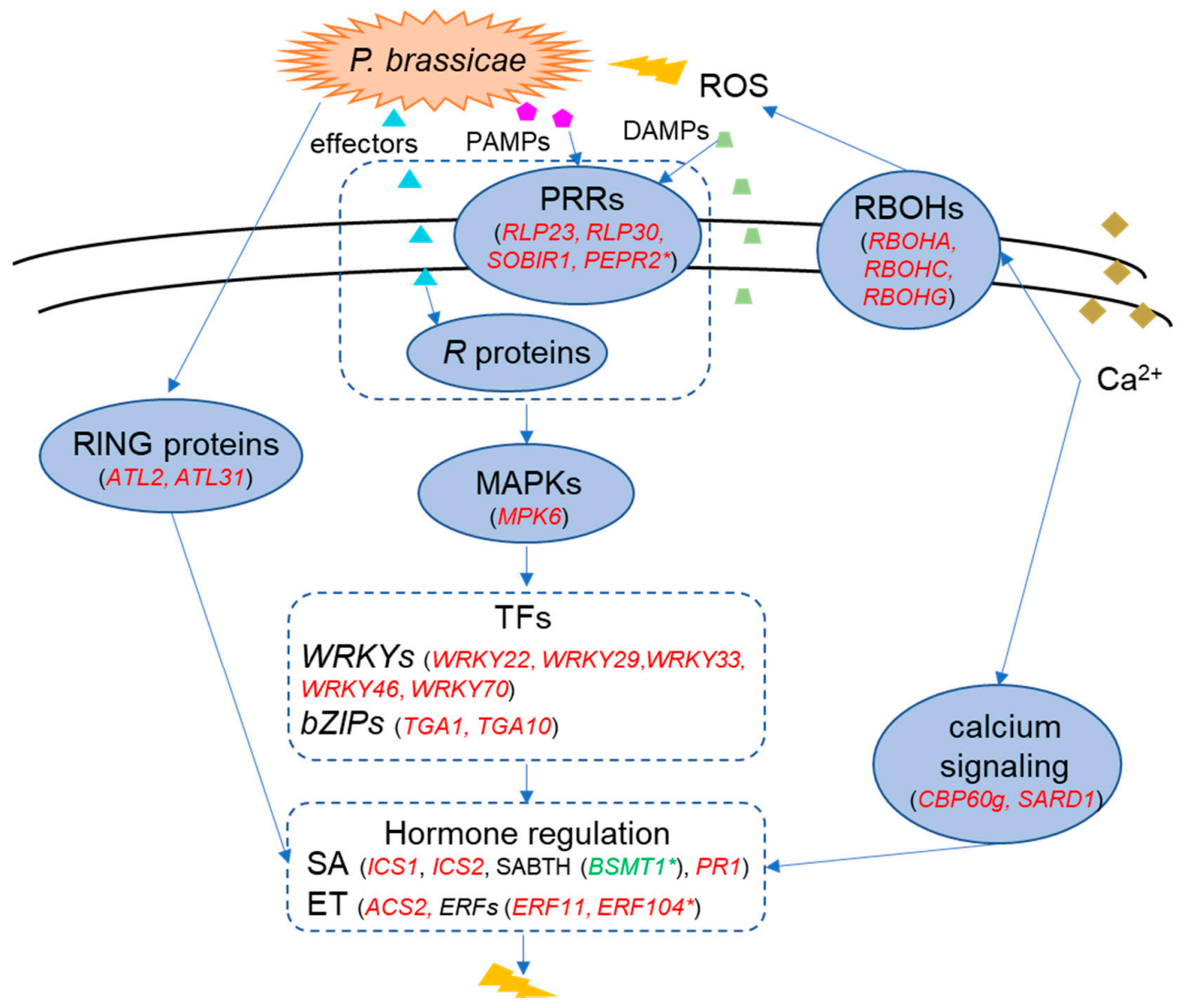

Figure 8. Model illustrating the major networks of the resistance response in the rutabaga 'Wilhelmsburger' to Plasmodiophora brassicae pathotype 3A. Important genes in each functional category are indicated in parentheses. Genes in red are upregulated, while those in green are downregulated in the resistant cultivar 'Wilhelmsburger.' Genes marked with an asterisk ${ }^{*}$ ) were inversely regulated in the susceptible cultivar 'Laurentian.' Lightning bolt symbols indicate defense responses. 
In conclusion, our study described genome-wide molecular responses of two rutabaga cultivars following inoculation with a widespread P. brassicae pathotype (3A) in western Canada. Our results provide insights into possible common defense responses in both cultivars, as well as cultivar-specific responses. Furthermore, we identified key defense genes that may be further validated using approaches such as gene editing to increase clubroot resistance. Ultimately, an improved understanding of $P$. brassicae/Brassica interactions will aid in the development of novel strategies for clubroot resistance breeding.

\section{Materials and Methods}

\subsection{Pathogen Material}

Plasmodiophora brassicae field isolate F3-14, originally collected from the CR canola 'L135C' and classified as pathotype 3A on the Canadian Clubroot Differential set [11], was used as the inoculum for this study. The isolate was stored as frozen $\left(-20^{\circ} \mathrm{C}\right)$ root galls and resting spore suspensions were prepared following Strelkov et al. (2006). Briefly, $100 \mathrm{~g}$ of the root galls were homogenized in $1 \mathrm{~L}$ distilled water $\left(\mathrm{dH}_{2} \mathrm{O}\right)$ in a blender for $2 \mathrm{~min}$, with the resulting homogenate filtered through eight layers of cheesecloth to remove any debris. The spore concentration was estimated with a hemocytometer and adjusted to about $1 \times 10^{7}$ spores $/ \mathrm{mL}$ with $\mathrm{dH}_{2} \mathrm{O}$.

\subsection{Plant Material and Inoculation}

All experiments were conducted with the rutabagas 'Wilhelmsburger' and 'Laurentian' (Bejo Seeds Inc., Oceano, CA, USA), which are resistant and susceptible, respectively, to pathotype 3A of P. brassicae [11]. The universally susceptible Chinese cabbage (Brassica rapa L. var. pekinensis) 'Granaat' (Bejo Seeds Inc., Oceano, CA, USA) was also included as a check in all inoculations, to ensure that the inoculum was viable and conditions were favorable for clubroot development. Eight-day-old seedlings, germinated in Petri dishes on moistened filter paper, were inoculated by the root dip method following Strelkov et al. (2006) [99]. The seedlings were briefly (10 s) dipped in the resting spore suspension and planted in pots $(6 \mathrm{~cm} \times 6 \mathrm{~cm} \times 6 \mathrm{~cm})$ filled with water-saturated Sunshine LA4 potting mix (SunGro Horticulture, Vancouver, BC, Canada). An additional $1 \mathrm{~mL}$ of inoculum was added to the base of each seedling with a micropipette to ensure strong disease pressure. Non-inoculated control plants were transferred directly from the Petri dishes to the potting mix. Plants were placed in insect cages $(47.5 \mathrm{~cm} \times 47.5 \mathrm{~cm} \times 93.0 \mathrm{~cm})$ to avoid potential insect infestations that could interfere with plant responses, and the experiment was conducted in a greenhouse under long day conditions $(16 \mathrm{~h})$ at $22{ }^{\circ} \mathrm{C}$. Roots were harvested at 7,14 , and 21 dai, washed with tap water and briefly dried on paper towels before being collected in Falcon tubes (Thermo Fisher Scientific, Waltham, MA, USA) and flash-frozen in liquid nitrogen. Five independent biological replicates were assigned for each treatment, with 27 pooled plants in each biological replicate. Clubroot symptom severity was evaluated at 45 dai on a 0-3 scale following Kuginuki et al. (1999), where $0=$ no visible galls, $1=\mathrm{a}$ few small galls, 2 = moderate galling, and 3 = severe galling [100]. Five independent biological replicates, with 30 plants per replicate, were used to rate symptom severity. Then, the severity rating results were used to calculate a DI using the formula of Horiuchi and Hori (1980) [101] as modified by Strelkov et al. (2006): DI $(\%)=\left[\left(n_{1} \times 1+n_{2} \times 2+n_{3} \times 3\right) /(n \times 3)\right] \times 100$, where $n_{1}, n_{2}$, and $n_{3}$ refer to the number of plants in each symptom severity class and $n$ refers to the total number of plants tested.

\subsection{RNA Extraction}

RNA was extracted from whole-root tissues of each host genotype at each time-point. Pooled tissues of all 27 plants of each biological replicate were ground to a fine powder in a mortar with a pestle in the presence of liquid nitrogen. The RNA was extracted from the $0.1 \mathrm{~mL}$ tissue homogenates using $1 \mathrm{~mL}$ Trizol (Ambion-Life Technologies, Carlsbad, CA, USA), $0.2 \mathrm{~mL}$ chloroform (Fisher Chemical, Fair Lawn, NJ, USA), and precipitated with $0.5 \mathrm{~mL}$ 2-propanol (Fisher Chemical, Fair Lawn, NJ, 
USA), followed by a cleanup step using RNeasy Mini Kit (Qiagen, Hilden, Germany) according to the manufacturer's instructions. The RNA was treated with DNAse (Qiagen, Hilden, Germany) for 15 min at room temperature to remove any DNA contamination, and the quantity, purity, and quality of the RNA were assessed with a NanoDrop 2000c Spectrophotometer (Thermo Fisher Scientific, Waltham, MA, USA) and the Agilent 2200 TapeStation system (Agilent, Santa Clara, CA, USA).

\subsection{RNA-Seq Analysis}

Three RNA samples (biological replicates) per treatment with RNA Integrity Numbers (RIN) $\geq 8.0$ were sent to Oklahoma State Genomics for library preparation and sequencing. Library preparation was performed using the KAPA mRNA HyperPrep Kit (KAPA Biosystems, Wilmington, MA, USA) following the manufacturer's instructions. Products were sequenced using a NextSeq 500 system (Illumina, San Diego, CA, USA) to generate 75-bp single-end reads. Reads were filtered with Trimmomatic [102] to remove low quality reads (phred score $<33$ ), adapters, leading/trailing low quality or unknown bases, and reads shorter than 36 bases. The quality of the filtered reads was checked using fastqc (http://www.bioinformatics.babraham.ac.uk/projects/fastqc/) and multiqc [103] prior to further analysis. The sequencing reads were deposited in the NCBI Sequence Read Archive (SRA) under accession number PRJNA641167.

Filtered reads from each fastq file were aligned to the $B$. napus reference genome (AST_PRJEB5043_v1) [104] using Tophat v. 2.11 [105]. Files of the mapped reads and reference genome were used as input for Cufflinks v. 2.2.1 [105], to detect differentially expressed transcripts between inoculated and non-inoculated samples. The Cufflinks analysis was performed with the option of GTF-guide and fragment bias correction using the downloaded reference genome structural annotation; the multi-readcorrection option was also used to weigh read mapping to various genomic locations more accurately. The resulting assembly files from all treatments and biological replicates were merged with Cuffmerge. The number of transcripts per sample was quantified using Cuffquant with the merged consensus transcripts file as a reference. Finally, differentially expressed transcript levels between inoculated and non-inoculated plants at each of the three time-points were detected with Cuffdiff. Expression levels were measured and normalized as reads per $\mathrm{kb}$ of transcript per million mapped reads (RPKM). Changes in expression with a $\log _{2} \mathrm{FC}>1$ or $\log _{2} \mathrm{FC}<-1$ and false discovery rate (Benjamini-Hockberg-corrected $q$-value) $<0.05$ were considered significant. When calculating $\log _{2} \mathrm{FC}$, a pseudo-count of RPKM (0.5) was added to each value to decrease the noise from genes with zero or very low expression.

\subsection{Validation of RNA-Seq Data by qRT-PCR}

To validate differential gene expression identified via RNA-seq, qRT-PCR analysis was performed on 10 genes across all treatments and samples (Table S4). These selected genes showed significant expression changes in RNA-seq in at least four of six comparison sets of inoculated vs. non-inoculated samples. Four biological replicates per treatment and time-point were used for cDNA synthesis. Oligo dT (18) (Thermo Fisher Scientific, Waltham, MA, USA)-primed cDNA was synthesized from 500 ng of total RNA using the RevertAid H Minus Reverse transcriptase (Thermo Fisher Scientific, Waltham, MA, USA) according to the manufacturer's protocol. The absence of genomic DNA contamination was confirmed by end-point PCR, using a $20 \mu \mathrm{L}$ reaction vol. with $2.5 \mathrm{ng}$ of cDNA, $0.2 \mathrm{mM}$ of each dNTP, $1 \times$ Buffer $+\mathrm{KCl}, 2.5 \mathrm{mM} \mathrm{MgCl} 2,1$ unit of high fidelity Taq polymerase, and $0.2 \mu \mathrm{M}$ of each forward and reverse primer of a clathrin adaptor complex (CAC) gene (Table S4). PCR analysis was performed with an initial denaturation step of $3 \mathrm{~min}$ at $95^{\circ} \mathrm{C}$ followed by 35 cycles of $30 \mathrm{sec}$ at $95^{\circ} \mathrm{C}, 30 \mathrm{sec}$ at $60^{\circ} \mathrm{C}$, and $1 \mathrm{~min}$ at $72{ }^{\circ} \mathrm{C}$, ending with an extension of $10 \mathrm{~min}$ at $72{ }^{\circ} \mathrm{C}$. Amplified products were subjected to agarose gel electrophoresis, which resulted in two distinct bands of $125 \mathrm{bp}$ (for cDNA) and $288 \mathrm{bp}$ (for the control genomic DNA).

Quantitative real-time PCR was performed on a ViiA 7 Real-Time PCR System (Applied Biosystems-Life Technologies, Waltham, MA, USA). Each reaction consisted of $5 \mu \mathrm{L}$ of in-house 
SYBR-green, $2.5 \mu \mathrm{L}$ of cDNA $(0.25 \mathrm{ng} / \mu \mathrm{L})$, and $2.5 \mu \mathrm{L}$ of paired primers $(3.2 \mu \mathrm{M})$. Reaction conditions included a denaturation step at $95^{\circ} \mathrm{C}$ for $5 \mathrm{~min}$ followed by 40 cycles at $95^{\circ} \mathrm{C}$ for $30 \mathrm{sec}$ and $60{ }^{\circ} \mathrm{C}$ for $1 \mathrm{~min}$; melting curves were generated using a cycle of $15 \mathrm{sec}$ at $95^{\circ} \mathrm{C}, 1 \mathrm{~min}$ at $60^{\circ} \mathrm{C}$, and $15 \mathrm{sec}$ at $95^{\circ} \mathrm{C}$. All qRT-PCR assays were conducted with four biological replicates and three technical replicates per biological replicate.

Fold changes between P. brassicae-inoculated samples and non-inoculated samples were calculated using the $2^{(-\Delta \Delta \mathrm{Ct})}$ method [106]. To select suitable housekeeping genes for normalization, primers from six previously published housekeeping genes were tested [107-109]: CAC, guanosine nucleotide diphosphate dissociation inhibitor 1 (GDI1), ubiquitin conjugating enzyme 9 (UBC9), ubiquitin conjugating enzyme 11 (UBC11), tubulin alpha-5 (TUA5), and vacuolar ATP synthase subunit E1 (VHA-E1).The stability of the genes across all samples was determined with Bestkeeper [110]. The most stable housekeeping genes were GDI1, UBC9, and TUA5. Relative expression of the target genes was quantified using the geometric mean of the cycle threshold $(\mathrm{Ct})$ values of the three selected housekeeping genes (Supplementary Table S4). To compare results obtained from RNA-seq and qRT-PCR analysis, Pearson correlations of $\log _{2}$ FC values were obtained from the two methods for each combination of treatment and time-point.

\subsection{Bioinformatic Analyses}

Transcripts were annotated using BLASTX (E value $\leq 1 \times 10^{-10}$ ) against the B. napus [104] and Arabidopsis (Arabidopsis thaliana) (TAIR10) [111] databases. Venn diagrams of DEGs were generated using the online tool jvenn (http://jvenn.toulouse.inra.fr/app/example.html) [112]. Principal component analysis of all samples was performed with the 'ggplot2' package in R.

MAPMAN [34] was used to display gene sets onto diagrams of metabolic pathways or other relevant processes. The B. napus gene IDs matching differentially expressed transcripts in each cultivar at each time-point were used as the input gene list and the gene IDs from the reference genome were used as the background reference. Multi-Experiment Viewer (MeV4.9) [113] was used to visualize $\log _{2} \mathrm{FC}$ of selected genes in both hosts through a time course. The distribution of genes showing opposite regulation patterns between the two cultivars was displayed using FunRich [114].

Supplementary Materials: Supplementary materials can be found at http:/www.mdpi.com/1422-0067/21/21/ $8381 /$ s1. Figure S1. PCA plots of variation between inoculated and control samples. (A) The PCA plot of 'Wilhelmsburger'; (B) The PCA plot of 'Laurentian'. Each condition has three biological replicates. Figure S2. Distribution of DEGs involved in the biotic stress response in the two hosts at 21 dai. (A) 'Wilhemsburger' and (B) 'Laurentian'. Values of log2 fold change for each gene are represented in a scale where red represents upregulation and blue represents downregulation. ABA, abscisic acid; JA, jasmonic acid; SA, salicylic acid; bZIP, basic region-leucine zipper; ERF, APETALA2/Ethylene-responsive element binding protein family; WRKY, WRKY transcription factor; MYB, MYB transcription factor; DOF, DNA-binding one zinc finger transcription factor; MAPK, mitogen-activated protein kinase; PR-protein, pathogenesis-related protein; R genes, resistance genes; Figure S3. Distribution of DEGs involved in lignin synthesis in the two hosts at 14 dai. (A) 'Wilhemsburger' and (B) 'Laurentian'. Values of $\log 2$ fold change for each gene are shown in a scale where red represents upregulation and blue represents downregulation. PAL, phenyl alanine ammonia-lyase; 4CL, 4-coumarate:CoA ligase; HCT, hydroxycinnamoyl-CoA shikimate/quinate hydroxycinnamoyl transferase; CCR1, cinnamyl-coenzyme A reductase; F5H, ferulate 5-hydroxylase; COMT, O-methyltransferase; CCOAMT, caffeoyl-CoA 3-O-methyltransferase; CAD, cinnamyl alcohol dehydrogenase. Table S1. Transcripts showing significant expression changes in at least one of six comparison sets of inoculated vs. non-inoculated samples. Table S2. Expression changes and annotations of transcripts matched to Figure 6. Table S3. Transcripts showing opposite regulation patterns in 'Wilhelmsburger' and 'Laurentian' at 7, 14 and 21 dai. Table S4. Genes used for PCR and qRT-PCR.

Author Contributions: Q.Z. and L.G.-G. designed the experiments. Q.Z. performed the experiments, conducted the analyses, and wrote the first version of the manuscript. L.G.-G. supervised all experiments and analyses, and edited several versions of the manuscript. V.M. assisted with the experiments and provided expertise with respect to inoculations and handling of the pathogen and greenhouse material. S.-F.H. helped secure project funding and contributed to the original experimental context. S.E.S. contributed to development of the research concept, provided guidance, and edited multiple versions of the manuscript. All authors have read and agreed to the published version of the manuscript. 
Funding: This research was funded by the Canadian Agricultural Partnership Program (Agriculture and Agri-Food Canada/Canola Council of Canada) and Alberta Agriculture and Forestry via the Strategic Research and Development Program.

Acknowledgments: In-kind contributions from the University of Alberta and Alberta Agriculture and Forestry are gratefully acknowledged.

Conflicts of Interest: The authors declare no conflict of interest.

\section{Abbreviations}

\begin{tabular}{|c|c|}
\hline $\mathrm{ABA}$ & Abscisic acid \\
\hline ACS2 & 1-amino-cyclopropane-1-carboxylate synthase 2 \\
\hline AOC2 & Allene oxide cyclase 2 \\
\hline AOS & Allene oxide synthase \\
\hline ATL & Arabidopsis Tóxicos en Levadura \\
\hline BAT5 & Bile acid transporter 5 \\
\hline BTL10 & BCA2Â zinc finger ATL 10 \\
\hline bZIP & Basic leucine zipper \\
\hline CAC & Clathrin adaptor complex \\
\hline CaMBP & Calmodulin-binding protein \\
\hline CBP & Calcium binding protein \\
\hline CBP60g & CaMBP 60-like G \\
\hline CCD & Canadian Clubroot Differential \\
\hline CR & Clubroot resistant \\
\hline CS & Clubroot susceptible \\
\hline $\mathrm{Ct}$ & Cycle threshold \\
\hline CYP79F1 & Cytochrome p450 79f1 \\
\hline CYP83A1 & Cytochrome P450, family 83, subfamily A, polypeptide 1 \\
\hline CYP94B1 & Cytochrome P450, family 94, subfamily B, polypeptide 1 \\
\hline CYP94C1 & Cytochrome P450, family 94, subfamily C, polypeptide 1 \\
\hline dai & Days after inoculation \\
\hline DAMP & Damage-associated molecular pattern \\
\hline DEG & Differentially expressed gene \\
\hline $\mathrm{dH} 2 \mathrm{O}$ & Distilled water \\
\hline DI & Disease index \\
\hline DIR6 & Dirigent protein 6 \\
\hline E2 & E2 ubiquitin-conjugating enzyme \\
\hline E3 & E3 ubiquitin ligase \\
\hline EREBP & APETALA2/ethylene-responsive element binding protein \\
\hline ERF & Ethylene response factor \\
\hline ET & Ethylene \\
\hline ETI & Effector-triggered immunity \\
\hline FAD7 & Fatty acid desaturase 7 \\
\hline GDI1 & Dissociation inhibitor 1 \\
\hline ICS & Isochorismate synthase \\
\hline JA & Jasmonic acid \\
\hline JA-Ile & Jasmonoyl-L-isoleucine \\
\hline $\log _{2} \mathrm{FC}$ & $\log _{2}$ fold-change \\
\hline MAPK & Mitogen-activated protein kinase \\
\hline MEKK & MAPK kinase kinase \\
\hline MKK & MAPK kinase \\
\hline MPK6 & Mitogen-activated protein kinase 6 \\
\hline MYB15 & MYB domain protein 15 \\
\hline
\end{tabular}


NLP Necrosis and ethylene-inducing peptide 1-like protein

NPR1 Nonexpresser of PR genes 1

NPR3 NPR1-like protein 3

OPR1 12-oxophytodienoate reductase 1

PAMP Pathogen-associated molecular pattern

PCA Principal component analysis

PEPR2 Pep 1 receptor 2

PLSP2A Plastidic type I signal peptidase 2A

PR Pathogenesis-related

PR1 Pathogenesis-related gene 1

PRR Pattern recognition receptor

PTI PAMP-triggered immunity

qRT-PCR Quantitative Real-Time PCR

QTL Quantitative resistance loci

R gene Resistance gene

$\mathrm{RBOH} \quad$ Respiratory burst oxidase homolog

RIN RNA integrity number

RLP Receptor-like protein

RNA-seq RNA sequencing

ROS Reactive oxygen species

RPKM Reads per kb of transcript per million mapped reads

SA Salicylic acid

SARD1 SAR deficient 1

SCFE1 Sclerotinia culture filtrate elicitor 1

SOBIR1 Protein suppressor of BIR1-1

SRA Sequence Read Archive

TF Transcription factor

TGA TGACG motif-binding protein

TIR-NBS-LRR Toll-interleukin receptor nucleotide-binding site-leucine-rich repeat

TUA5 Tubulin alpha-5

UBC Ubiquitin conjugating enzyme

VHA-E1 Vacuolar ATP synthase subunit E1

WAVH1 WAV3 homolog 1

\section{References}

1. Dixon, G.R. The occurrence and economic impact of Plasmodiophora brassicae and clubroot disease. J. Plant Growth Regul. 2009, 28, 194-202. [CrossRef]

2. Howard, R.J.; Strelkov, S.E.; Harding, M.W. Clubroot of cruciferous crops - new perspectives on an old disease. Can. J. Plant Pathol. 2010, 32, 43-57. [CrossRef]

3. Strelkov, S.E.; Hwang, S.-F. Clubroot in the Canadian canola crop: 10 years into the outbreak. Can. J. Plant Pathol. 2014, 36, 27-36. [CrossRef]

4. Canola Council of Canada-Industry Overview. Available online: https://www.canolacouncil.org/marketsstats/industry-overview/ (accessed on 12 September 2020).

5. Strelkov, S.E.; Hwang, S.-F.; Howard, R.J.; Hartman, M.; Turkington, T.K. Progress towards the sustainable management of clubroot (Plasmodiophora brassicae) of canola on the Canadian prairies. Prairie Soils Crop. J. 2011, 4, 114-121.

6. Hwang, S.-F.; Howard, R.J.; Strelkov, S.E.; Gossen, B.D.; Peng, G. Management of clubroot (Plasmodiophora brassicae) on canola (Brassica napus) in western Canada. Can. J. Plant Pathol. 2014, 36, 49-65. [CrossRef]

7. Peng, G.; Lahlali, R.; Hwang, S.-F.; Pageau, D.; Hynes, R.K.; McDonald, M.R.; Gossen, B.D.; Strelkov, S.E. Crop rotation, cultivar resistance, and fungicides/biofungicides for managing clubroot (Plasmodiophora brassicae) on canola. Can. J. Plant Pathol. 2014, 36, 99-112. [CrossRef]

8. Canola Council of Canada-Control Clubroot. Available online: https://www.canolacouncil.org/canolaencyclopedia/diseases/clubroot/control-clubroot/\#pathotypes (accessed on 4 July 2019). 
9. Fredua-Agyeman, R.; Hwang, S.-F.; Strelkov, S.E.; Zhou, Q.; Feindel, D. Potential loss of clubroot resistance genes from donor parent Brassica rapa subsp. rapifera (ECD 04) during doubled haploid production. Plant Pathol. 2018, 67, 892-901. [CrossRef]

10. Strelkov, S.E.; Hwang, S.-F.; Manolii, V.P.; Cao, T.; Feindel, D. Emergence of new virulence phenotypes of Plasmodiophora brassicae on canola (Brassica napus) in Alberta, Canada. Eur. J. Plant Pathol. 2016, 145, 517-529. [CrossRef]

11. Strelkov, S.E.; Hwang, S.-F.; Manolii, V.P.; Cao, T.; Fredua-Agyeman, R.; Harding, M.W.; Peng, G.; Gossen, B.D.; Mcdonald, M.R.; Feindel, D. Virulence and pathotype classification of Plasmodiophora brassicae populations collected from clubroot resistant canola (Brassica napus) in Canada. Can. J. Plant Pathol. 2018, 40, $284-298$. [CrossRef]

12. Strelkov, S.E.; Hwang, S.-F.; Manolii, V.P.; Turnbull, G.; Fredua-Agyeman, R.; Hollman, K.; Kaus, S. Characterization of clubroot (Plasmodiophora brassicae) from canola (Brassica napus) in the Peace Country of Alberta, Canada. Can. J. Plant Pathol. 2020, 1-7. [CrossRef]

13. Dodds, P.N.; Rathjen, J.P. Plant immunity: Towards an integrated view of plant-pathogen interactions. Nat. Rev. Genet. 2010, 11, 539-548. [CrossRef] [PubMed]

14. Zipfel, C. Plant pattern-recognition receptors. Trends Immunol. 2014, 35, 345-351. [CrossRef]

15. Ueno, H.; Matsumoto, E.; Aruga, D.; Kitagawa, S.; Matsumura, H.; Hayashida, N. Molecular characterization of the CRa gene conferring clubroot resistance in Brassica rapa. Plant Mol. Biol. 2012, 80, 621-629. [CrossRef]

16. Hatakeyama, K.; Suwabe, K.; Tomita, R.N.; Kato, T.; Nunome, T.; Fukuoka, H.; Matsumoto, S. Identification and characterization of Crr1a, a gene for resistance to clubroot disease (Plasmodiophora brassicae Woronin) in Brassica rapa L. PLoS ONE 2013, 8, e54745. [CrossRef] [PubMed]

17. Neik, T.X.; Barbetti, M.J.; Batley, J. Current status and challenges in identifying disease resistance genes in Brassica napus. Front. Plant Sci. 2017, 8, 1788. [CrossRef] [PubMed]

18. Yu, F.; Zhang, X.; Peng, G.; Falk, K.C.; Strelkov, S.E.; Gossen, B.D. Genotyping-by-sequencing reveals three QTL for clubroot resistance to six pathotypes of Plasmodiophora brassicae in Brassica rapa. Sci. Rep. 2017, 7, 4516. [CrossRef]

19. Yu, F.; Zhang, X.; Huang, Z.; Chu, M.; Song, T.; Falk, K.C.; Deora, A.; Chen, Q.; Zhang, Y.; McGregor, L.; et al. Identification of genome-wide variants and discovery of variants associated with Brassica rapa clubroot resistance gene Rcr1 through bulked segregant RNA sequencing. PLoS ONE 2016, 11, e0153218. [CrossRef] [PubMed]

20. Huang, Z.; Peng, G.; Liu, X.; Deora, A.; Falk, K.C.; Gossen, B.D.; McDonald, M.R.; Yu, F. Fine mapping of a clubroot resistance gene in Chinese cabbage using SNP markers identified from bulked segregant RNA sequencing. Front. Plant Sci. 2017, 8, 1448. [CrossRef]

21. Pang, W.; Fu, P.; Li, X.; Zhan, Z.; Yu, S.; Piao, Z. Identification and mapping of the clubroot resistance gene CRd in Chinese cabbage (Brassica rapa ssp. pekinensis). Front. Plant Sci. 2018, 9, 653. [CrossRef]

22. Chang, A.; Lamara, M.; Wei, Y.; Hu, H.; Parkin, I.A.P.; Gossen, B.D.; Peng, G.; Yu, F. Clubroot resistance gene Rcr6 in Brassica nigra resides in a genomic region homologous to chromosome A08 in B. rapa. BMC Plant Biol. 2019, 19, 224. [CrossRef]

23. Boyd, L.A.; Ridout, C.; O'Sullivan, D.M.; Leach, J.E.; Leung, H. Plant-pathogen interactions: Disease resistance in modern agriculture. Trends Genet. 2013, 29, 233-240. [CrossRef]

24. Chen, J.; Pang, W.; Chen, B.; Zhang, C.; Piao, Z. Transcriptome analysis of Brassica rapa near-isogenic lines carrying clubroot-resistant and-susceptible alleles in response to Plasmodiophora brassicae during early infection. Front. Plant Sci. 2016, 6, 1183. [CrossRef]

25. Luo, Y.; Dong, D.; Su, Y.; Wang, X.; Peng, Y.; Peng, J.; Zhou, C. Transcriptome analysis of Brassica juncea var. tumida Tsen responses to Plasmodiophora brassicae primed by the biocontrol strain Zhihengliuella aestuarii. Funct. Integr. Genom. 2018, 18, 301-314. [CrossRef]

26. Summanwar, A.; Basu, U.; Rahman, H.; Kav, N. Identification of lncRNAs responsive to infection by Plasmodiophora brassicae in clubroot-susceptible and -resistant Brassica napus lines carrying resistance introgressed from rutabaga. Mol. Plant-Microbe Interact. 2019, 32, 1360-1377. [CrossRef]

27. Rahman, H.; Peng, G.; Yu, F.; Falk, K.C.; Kulkarni, M.; Selvaraj, G. Genetics and breeding for clubroot resistance in Canadian spring canola (Brassica napus L.). Can. J. Plant Pathol. 2014, 36, 122-134. [CrossRef] 
28. Fredua-Agyeman, R.; Yu, Z.; Hwang, S.-F.; Strelkov, S.E. Genome-wide mapping of loci associated with resistance to clubroot in Brassica napus ssp. napobrassica (rutabaga) accessions from Nordic countries. Front. Plant Sci. 2020, 11, 742. [CrossRef]

29. Ayers, C.W.; Lelacheur, K.E. Genetics of resistance in rutabaga to two races of Plasmodiophora brassicae. Can. J. Plant Sci. 1972, 52, 897-900. [CrossRef]

30. Hasan, M.J.; Rahman, H. Genetics and molecular mapping of resistance to Plasmodiophora brassicae pathotypes 2, 3, 5, 6, and 8 in rutabaga (Brassica napus var. napobrassica). Genome 2016, 59, 805-815. [CrossRef]

31. Galindo-González, L.; Manolii, V.; Hwang, S.-F.; Strelkov, S.E. Response of Brassica napus to Plasmodiophora brassicae involves salicylic acid-mediated immunity: An RNA-seq-based study. Front. Plant Sci. 2020, 11, 1025. [CrossRef]

32. Song, T.; Chu, M.; Lahlali, R.; Yu, F.; Peng, G. Shotgun label-free proteomic analysis of clubroot (Plasmodiophora brassicae) resistance conferred by the gene Rcr1 in Brassica rapa. Front. Plant Sci. 2016, 7, 1013. [CrossRef]

33. Mei, J.; Guo, Z.; Wang, J.; Feng, Y.; Ma, G.; Zhang, C.; Qian, W.; Chen, G. Understanding the resistance mechanism in Brassica napus to Clubroot Caused by Plasmodiophora brassicae. Phytopathology 2019, 109, 810-818. [CrossRef]

34. Thimm, O.; Bläsing, O.; Gibon, Y.; Nagel, A.; Meyer, S.; Krüger, P.; Selbig, J.; Müller, L.A.; Rhee, S.Y.; Stitt, M. MAPMAN: A user-driven tool to display genomics data sets onto diagrams of metabolic pathways and other biological processes. Plant J. 2004, 37, 914-939. [CrossRef]

35. Berens, M.L.; Berry, H.M.; Mine, A.; Argueso, C.T.; Tsuda, K. Evolution of hormone signaling networks in plant defense. Annu. Rev. Phytopathol. 2017, 55, 401-425. [CrossRef]

36. Wang, J.H.; Gu, K.D.; Han, P.L.; Yu, J.Q.; Wang, C.K.; Zhang, Q.Y.; You, C.X.; Hu, D.G.; Hao, Y.J. Apple ethylene response factor MdERF11 confers resistance to fungal pathogen Botryosphaeria dothidea. Plant Sci. 2020, 291, 110351. [CrossRef]

37. Fu, P.; Piao, Y.; Zhan, Z.; Zhao, Y.; Pang, W.; Li, X.; Piao, Z. Transcriptome profile of Brassica rapa L. reveals the involvement of jasmonic acid, ethylene, and brassinosteroid signaling pathways in clubroot resistance. Agronomy 2019, 9, 589. [CrossRef]

38. Guerreiro, A.; Figueiredo, J.; Sousa Silva, M.; Figueiredo, A. Linking jasmonic acid to grapevine resistance against the biotrophic oomycete Plasmopara viticola. Front. Plant Sci. 2016, 7, 565. [CrossRef] [PubMed]

39. Jubault, M.; Lariagon, C.; Taconnat, L.; Renou, J.-P.P.; Gravot, A.; Delourme, R.; Manzanares-Dauleux, M.J. Partial resistance to clubroot in Arabidopsis is based on changes in the host primary metabolism and targeted cell division and expansion capacity. Funct. Integr. Genom. 2013, 13, 191-205. [CrossRef]

40. Lemarié, S.; Robert-Seilaniantz, A.; Lariagon, C.; Lemoine, J.; Marnet, N.; Jubault, M.; Manzanares-Dauleux, M.J.; Gravot, A. Both the jasmonic acid and the salicylic acid pathways contribute to resistance to the biotrophic clubroot agent Plasmodiophora brassicae in Arabidopsis. Plant Cell Physiol. 2015, 56, 2158-2168. [CrossRef]

41. Jia, H.; Wei, X.; Yang, Y.; Yuan, Y.; Wei, F.; Zhao, Y.; Yang, S.; Yao, Q.; Wang, Z.; Tian, B.; et al. Root RNA-seq analysis reveals a distinct transcriptome landscape between clubroot-susceptible and clubroot-resistant Chinese cabbage lines after Plasmodiophora brassicae infection. Plant Soil 2017, 421, 93-105. [CrossRef]

42. Garcion, C.; Lohmann, A.; Lamodière, E.; Catinot, J.; Buchala, A.; Doermann, P.; Métraux, J.P. Characterization and biological function of the ISOCHORISMATE SYNTHASE2 gene of Arabidopsis. Plant Physiol. 2008, 147, 1279-1287. [CrossRef]

43. Qu, L.; Li, S.; Xing, S. Methylation of phytohormones by the SABATH methyltransferases. Chin. Sci. Bull. 2010, 55, 2211-2218. [CrossRef]

44. Dempsey, D.A.; Vlot, A.C.; Wildermuth, M.C.; Klessig, D.F. Salicylic acid biosynthesis and metabolism. Arab. Book 2011, 9, e0156. [CrossRef]

45. Djavaheri, M.; Ma, L.; Klessig, D.F.; Mithöfer, A.; Gropp, G.; Borhan, H. Mimicking the host regulation of salicylic acid: A virulence strategy by the clubroot pathogen Plasmodiophora brassicae. Mol. Plant-Microbe Interact. 2019, 32, 296-305. [CrossRef] [PubMed]

46. Chu, M.; Song, T.; Falk, K.C.; Zhang, X.; Liu, X.; Chang, A.; Lahlali, R.; McGregor, L.; Gossen, B.D.; Yu, F. Fine mapping of Rcr1 and analyses of its effect on transcriptome patterns during infection by Plasmodiophora brassicae. BMC Genom. 2014, 15, 1166. [CrossRef] [PubMed] 
47. Knaust, A.; Ludwig-Müller, J. The ethylene signaling pathway is needed to restrict root gall growth in Arabidopsis after infection with the obligate biotrophic protist Plasmodiophora brassicae. J. Plant Growth Regul. 2013, 32, 9-21. [CrossRef]

48. Bethke, G.; Unthan, T.; Uhrig, J.F.; Pöschl, Y.; Gust, A.A.; Scheel, D.; Lee, J. Flg22 regulates the release of an ethylene response factor substrate from MAP kinase 6 in Arabidopsis thaliana via ethylene signaling. Proc. Natl. Acad. Sci. USA 2009, 106, 8067-8072. [CrossRef] [PubMed]

49. Su, T.; Yu, S.; Wang, W.; Li, P.; Zhang, F.; Yu, Y.; Zhang, D.; Zhao, X. ITRAQ analysis of protein profile during the secondary stage of infection of Plasmodiophora brassicae in Chinese cabbage (Brassica rapa subsp. pekinensis). J. Plant Pathol. 2018, 100, 533-542. [CrossRef]

50. Zhang, W.; Fraiture, M.; Kolb, D.; Löffelhardt, B.; Desaki, Y.; Boutrot, F.F.G.; Tör, M.; Zipfel, C.; Gust, A.A.; Brunner, F. Arabidopsis RECEPTOR-LIKE PROTEIN30 and receptor-like kinase SUPPRESSOR OF BIR1-1/EVERSHED mediate innate immunity to necrotrophic fungi. Plant Cell 2013, 25, 4227-4241. [CrossRef]

51. Albert, I.; Böhm, H.; Albert, M.; Feiler, C.E.; Imkampe, J.; Wallmeroth, N.; Brancato, C.; Raaymakers, T.M.; Oome, S.; Zhang, H.; et al. An RLP23-SOBIR1-BAK1 complex mediates NLP-triggered immunity. Nat. Plants 2015, 1, 1-9. [CrossRef]

52. Vlot, A.C.; Dempsey, D.A.; Klessig, D.F. Salicylic acid, a multifaceted hormone to combat disease. Annu. Rev. Phytopathol. 2009, 47, 177-206. [CrossRef]

53. Ding, Y.; Sun, T.; Ao, K.; Peng, Y.; Zhang, Y.Y.; Li, X.; Zhang, Y.Y. Opposite roles of salicylic acid receptors NPR1 and NPR3/NPR4 in transcriptional regulation of plant immunity. Cell 2018, 173, 1454-1467.e15. [CrossRef]

54. Paniagua, C.; Bilkova, A.; Jackson, P.; Dabravolski, S.; Riber, W.; Didi, V.; Houser, J.; Gigli-Bisceglia, N.; Wimmerova, M.; Budínská, E.; et al. Dirigent proteins in plants: Modulating cell wall metabolism during abiotic and biotic stress exposure. J. Exp. Bot. 2017, 68, 3287-3301. [CrossRef]

55. Lahlali, R.; Song, T.; Chu, M.; Yu, F.; Kumar, S.; Karunakaran, C.; Peng, G. Evaluating changes in cell-wall components associated with clubroot resistance using fourier transform infrared spectroscopy and RT-PCR. Int. J. Mol. Sci. 2017, 18, 2058. [CrossRef] [PubMed]

56. Ciaghi, S.; Schwelm, A.; Neuhauser, S. Transcriptomic response in symptomless roots of clubroot infected kohlrabi (Brassica oleracea var. gongylodes) mirrors resistant plants. BMC Plant Biol. 2019, 19, 288. [CrossRef]

57. Dakouri, A.; Zhang, X.; Peng, G.; Falk, K.C.; Gossen, B.D.; Strelkov, S.E.; Yu, F. Analysis of genome-wide variants through bulked segregant RNA sequencing reveals a major gene for resistance to Plasmodiophora brassicae in Brassica oleracea. Sci. Rep. 2018, 8, 17657. [CrossRef]

58. Liu, Z.; Wu, Y.; Yang, F.; Zhang, Y.; Chen, S.; Xie, Q.; Tian, X.; Zhou, J.M. BIK1 interacts with PEPRs to mediate ethylene-induced immunity. Proc. Natl. Acad. Sci. USA 2013, 110, 6205-6210. [CrossRef]

59. Zipfel, C. Combined roles of ethylene and endogenous peptides in regulating plant immunity and growth. Proc. Natl. Acad. Sci. USA 2013, 110. [CrossRef]

60. Liebrand, T.W.H.; Van Den Berg, G.C.M.; Zhang, Z.; Smit, P.; Cordewener, J.H.G.; America, A.H.P.; Sklenar, J.; Jones, A.M.E.; Tameling, W.I.L.; Robatzek, S.; et al. Receptor-like kinase SOBIR1/EVR interacts with receptor-like proteins in plant immunity against fungal infection. Proc. Natl. Acad. Sci. USA 2013, 110, 10010-10015. [CrossRef]

61. Stael, S.; Kmiecik, P.; Willems, P.; Van Der Kelen, K.; Coll, N.S.; Teige, M.; Van Breusegem, F. Plant innate immunity-sunny side up? Trends Plant Sci. 2015, 20, 3-11. [CrossRef]

62. Zhang, X.; Liu, Y.; Fang, Z.; Li, Z.; Yang, L.; Zhuang, M.; Zhang, Y.; Lv, H. Comparative transcriptome analysis between broccoli (Brassica oleracea var. italica) and wild cabbage (Brassica macrocarpa Guss.) in response to Plasmodiophora brassicae during different infection stages. Front. Plant Sci. 2016, 7, 1929. [CrossRef] [PubMed]

63. Ning, Y.; Wang, Y.; Fang, Z.; Zhuang, M.; Zhang, Y.; Lv, H.; Liu, Y.; Li, Z.; Yang, L. Comparative transcriptome analysis of cabbage (Brassica oleracea var. capitata) infected by Plasmodiophora brassicae reveals drastic defense response at secondary infection stage. Plant Soil 2019, 443, 167-183. [CrossRef]

64. Birkenbihl, R.P.; Liu, S.; Somssich, I.E. Transcriptional events defining plant immune responses. Curr. Opin. Plant Biol. 2017, 38, 1-9. [CrossRef]

65. Hu, Y.; Dong, Q.; Yu, D. Arabidopsis WRKY46 coordinates with WRKY70 and WRKY53 in basal resistance against pathogen Pseudomonas syringae. Plant Sci. 2012, 185, 288-297. [CrossRef] 
66. Asai, T.; Tena, G.; Plotnikova, J.; Willmann, M.R.; Chiu, W.L.; Gomez-Gomez, L.; Boller, T.; Ausubel, F.M.; Sheen, J.; Gomez-Gomez, L.; et al. MAP kinase signalling cascade in Arabidopsis innate immunity. Nature 2002, 415, 977-983. [CrossRef]

67. Zheng, Z.; Qamar, S.A.; Chen, Z.; Mengiste, T. Arabidopsis WRKY33 transcription factor is required for resistance to necrotrophic fungal pathogens. Plant J. 2006, 48, 592-605. [CrossRef] [PubMed]

68. Li, G.; Meng, X.; Wang, R.; Mao, G.; Han, L.; Liu, Y.; Zhang, S. Dual-level regulation of ACC synthase activity by MPK3/MPK6 cascade and its downstream WRKY transcription factor during ethylene induction in Arabidopsis. PLoS Genet. 2012, 8, e1002767. [CrossRef]

69. Sheikh, A.H.; Eschen-Lippold, L.; Pecher, P.; Hoehenwarter, W.; Sinha, A.K.; Scheel, D.; Lee, J. Regulation of WRKY46 transcription factor function by mitogen-activated protein kinases in Arabidopsis thaliana. Front. Plant Sci. 2016, 7, 61. [CrossRef] [PubMed]

70. Alves, M.; Dadalto, S.; Gonçalves, A.; De Souza, G.; Barros, V.; Fietto, L. Plant bZIP transcription factors responsive to pathogens: A review. Int. J. Mol. Sci. 2013, 14, 7815-7828. [CrossRef]

71. Mandal, A.; Sharma, N.; Muthamilarasan, M.; Prasad, M. Ubiquitination: A tool for plant adaptation to changing environments. Nucleus 2018, 61, 253-260. [CrossRef]

72. Zhao, Y.; Bi, K.; Gao, Z.; Chen, T.; Liu, H.; Xie, J.; Cheng, J.; Fu, Y.; Jiang, D. Transcriptome analysis of Arabidopsis thaliana in response to Plasmodiophora brassicae during early infection. Front. Microbiol. 2017, 8 , 673. [CrossRef]

73. Guzmán, P. The prolific ATL family of RING-H2 ubiquitin ligases. Plant Signal. Behav. 2012, 7, $1014-1021$. [CrossRef]

74. Serrano, M.; Guzmán, P. Isolation and gene expression analysis of Arabidopsis thaliana mutants with constitutive expression of ATL2, an early elicitor-response RING-H2 zinc-finger gene. Genetics 2004, 167, 919-929. [CrossRef]

75. Maekawa, S.; Sato, T.; Asada, Y.; Yasuda, S.; Yoshida, M.; Chiba, Y.; Yamaguchi, J. The Arabidopsis ubiquitin ligases ATL31 and ATL6 control the defense response as well as the carbon/nitrogen response. Plant Mol. Biol. 2012, 79, 217-227. [CrossRef]

76. Irani, S.; Trost, B.; Waldner, M.; Nayidu, N.; Tu, J.; Kusalik, A.J.; Todd, C.D.; Wei, Y.; Bonham-Smith, P.C. Transcriptome analysis of response to Plasmodiophora brassicae infection in the Arabidopsis shoot and root. BMC Genom. 2018, 19, 23. [CrossRef] [PubMed]

77. Bi, K.; He, Z.; Gao, Z.; Zhao, Y.; Fu, Y.; Cheng, J.; Xie, J.; Jiang, D.; Chen, T. Integrated omics study of lipid droplets from Plasmodiophora brassicae. Sci. Rep. 2016, 6, 36965. [CrossRef]

78. Wasternack, C.; Stenzel, I.; Hause, B.; Hause, G.; Kutter, C.; Maucher, H.; Neumerkel, J.; Feussner, I.; Miersch, O. The wound response in tomato-role of jasmonic acid. J. Plant Physiol. 2006, 163, 297-306. [CrossRef]

79. Weber, H. Fatty acid-derived signals in plants. Trends Plant Sci. 2002, 7, 217-224. [CrossRef]

80. Avila, C.A.; Arévalo-Soliz, L.M.; Jia, L.; Navarre, D.A.; Chen, Z.; Howe, G.A.; Meng, Q.W.; Smith, J.E.; Goggin, F.L. Loss of function of FATTY ACID DESATURASE7 in tomato enhances basal aphid resistance in a salicylate-dependent manner. Plant Physiol. 2012, 158, 2028-2041. [CrossRef]

81. Gutterson, N.; Reuber, T.L. Regulation of disease resistance pathways by AP2/ERF transcription factors. Curr. Opin. Plant Biol. 2004, 7, 465-471. [CrossRef]

82. Li, L.; Long, Y.; Li, H.; Wu, X. Comparative transcriptome analysis reveals key pathways and hub genes in rapeseed during the early stage of Plasmodiophora brassicae infection. Front. Genet. 2020, 10, 1275. [CrossRef]

83. Chezem, W.R.; Memon, A.; Li, F.S.; Weng, J.K.; Clay, N.K. SG2-type R2R3-MYB transcription factor MYB15 controls defense-induced lignification and basal immunity in Arabidopsis. Plant Cell 2017, 29, 1907-1926. [CrossRef]

84. Luo, Y.; Bai, R.; Li, J.; Yang, W.; Li, R.; Wang, Q.; Zhao, G.; Duan, D. The transcription factor MYB15 is essential for basal immunity (PTI) in Chinese wild grape. Planta 2019, 1, 1889-1902. [CrossRef]

85. Hsu, S.-C.; Endow, J.K.; Ruppel, N.J.; Roston, R.L.; Baldwin, A.J.; Inoue, K. Functional diversification of thylakoidal processing peptidases in Arabidopsis thaliana. PLoS ONE 2011, 6, e27258. [CrossRef] [PubMed]

86. Moon, J.Y.; Kim, S.T.; Choi, G.J.; Kwon, S.-Y.; Cho, H.S.; Kim, H.-S.; Moon, J.S.; Park, J.M. Comparative proteomic analysis of host responses to Plasmodiophora brassicae infection in susceptible and resistant Brassica oleracea. Plant Biotechnol. Rep. 2020, 14, 263-274. [CrossRef] 
87. Fu, F.; Liu, X.; Wang, R.; Zhai, C.; Peng, G.; Yu, F.; Fernando, W.G.D. Fine mapping of Brassica napus blackleg resistance gene Rlm1 through bulked segregant RNA sequencing. Sci. Rep. 2019, 9, 14600. [CrossRef] [PubMed]

88. Koo, A.J.K.; Howe, G.A. Catabolism and deactivation of the lipid-derived hormone jasmonoyl-isoleucine. Front. Plant Sci. 2012, 3, 19. [CrossRef]

89. Hirano, T.; Kimura, S.; Sakamoto, T.; Okamoto, A.; Nakayama, T.; Matsuura, T.; Ikeda, Y.; Takeda, S.; Suzuki, Y.; Ohshima, I.; et al. Reprogramming of the developmental program of Rhus javanica during initial stage of gall induction by Schlechtendalia chinensis. Front. Plant Sci. 2020, 11, 471. [CrossRef] [PubMed]

90. Chen, S.; Glawischnig, E.; Jørgensen, K.; Naur, P.; Jørgensen, B.; Olsen, C.E.; Hansen, C.H.; Rasmussen, H.; Pickett, J.A.; Halkier, B.A. CYP79F1 and CYP79F2 have distinct functions in the biosynthesis of aliphatic glucosinolates in Arabidopsis. Plant J. 2003, 33, 923-937. [CrossRef]

91. Ludwig-Müller, J.; Prinsen, E.; Rolfe, S.A.; Scholes, J.D. Metabolism and plant hormone action during clubroot disease. J. Plant Growth Regul. 2009, 28, 229-244. [CrossRef]

92. Gigolashvili, T.; Yatusevich, R.; Rollwitz, I.; Humphry, M.; Gershenzon, J.; Flügge, U.I. The plastidic bile acid transporter 5 is required for the biosynthesis of methionine-derived glucosinolates in Arabidopsis thaliana. Plant Cell 2009, 21, 1813-1829. [CrossRef]

93. Hemm, M.R.; Ruegger, M.O.; Chapple, C. The Arabidopsis ref2 mutant is defective in the gene encoding CYP83A1 and shows both phenylpropanoid and glucosinolate phenotypes. Plant Cell 2003, 15, 179-194. [CrossRef]

94. Bishop, J.G.; Dean, A.M.; Mitchell-Olds, T. Rapid evolution in plant chitinases: Molecular targets of selection in plant-pathogen coevolution. Proc. Natl. Acad. Sci. USA 2000, 97, 5322-5327. [CrossRef]

95. Schwelm, A.; Fogelqvist, J.; Knaust, A.; Jülke, S.; Lilja, T.; Bonilla-Rosso, G.; Karlsson, M.; Shevchenko, A.; Dhandapani, V.; Choi, S.R.; et al. The Plasmodiophora brassicae genome reveals insights in its life cycle and ancestry of chitin synthases. Sci. Rep. 2015, 5, 11153. [CrossRef]

96. Chen, J.; Piao, Y.; Liu, Y.; Li, X.; Piao, Z. Genome-wide identification and expression analysis of chitinase gene family in Brassica rapa reveals its role in clubroot resistance. Plant Sci. 2018, 270, 257-267. [CrossRef]

97. Peng, Y.; Van Wersch, R.; Zhang, Y. Convergent and divergent signaling in PAMP-triggered immunity and effector-triggered immunity. Mol. Plant-Microbe Interact. 2018, 31, 403-409. [CrossRef]

98. Turjanski, A.G.; Vaqueánd, J.P.; Gutkind, J.S. MAP kinases and the control of nuclear events. Oncogene 2007, 26, 3240-3253. [CrossRef]

99. Strelkov, S.E.; Tewari, J.P.; Smith-Degenhardt, E. Characterization of Plasmodiophora brassicae populations from Alberta, Canada. Can. J. Plant Pathol. 2006, 28, 467-474. [CrossRef]

100. Kuginuki, Y.; Yoshikawa, H.; Hirai, M. Variation in virulence of Plasmodiophora brassicae in Japan tested with clubroot-resistant cultivars of Chinese cabbage (Brassica rapa L. ssp. pekinensis). Eur. J. Plant Pathol. 1999, 105, 327-332. [CrossRef]

101. Horiuchi, S.; Hori, M. A simple greenhouse technique for obtaining high levels of clubroot incidence. Bull. Chugoku Natl. Agric. Exp. Stn. Ser. E 1980, 17, 33-35. [CrossRef]

102. Bolger, A.M.; Lohse, M.; Usadel, B. Trimmomatic: A flexible trimmer for Illumina sequence data. Bioinformatics 2014, 30, 2114-2120. [CrossRef]

103. Ewels, P.; Magnusson, M.; Lundin, S.; Käller, M. MultiQC: Summarize analysis results for multiple tools and samples in a single report. Bioinformatics 2016, 32, 3047-3048. [CrossRef] [PubMed]

104. Chalhoub, B.; Denoeud, F.; Liu, S.; Parkin, I.A.P.; Tang, H.; Wang, X.; Chiquet, J.; Belcram, H.; Tong, C.; Samans, B.; et al. Early allopolyploid evolution in the post-neolithic Brassica napus oilseed genome. Science 2014, 345, 950-953. [CrossRef]

105. Trapnell, C.; Roberts, A.; Goff, L.; Pertea, G.; Kim, D.; Kelley, D.R.; Pimentel, H.; Salzberg, S.L.; Rinn, J.L.; Pachter, L. Differential gene and transcript expression analysis of RNA-seq experiments with TopHat and Cufflinks. Nat. Protoc. 2012, 7, 562-578. [CrossRef]

106. Livak, K.J.; Schmittgen, T.D. Analysis of relative gene expression data using real-time quantitative PCR and the 2- $\Delta \Delta \mathrm{CT}$ method. Methods 2001, 25, 402-408. [CrossRef]

107. Yang, H.; Liu, J.; Huang, S.; Guo, T.; Deng, L.; Hua, W. Selection and evaluation of novel reference genes for quantitative reverse transcription PCR (qRT-PCR) based on genome and transcriptome data in Brassica napus L. Gene 2014, 538, 113-122. [CrossRef] [PubMed] 
108. Chandna, R.; Augustine, R.; Bisht, N.C. Evaluation of candidate reference genes for gene expression normalization in Brassica juncea using real time quantitative RT-PCR. PLoS ONE 2012, 7, e36918. [CrossRef]

109. Han, P.P.; Qin, L.; Li, Y.S.; Liao, X.S.; Xu, Z.X.; Hh, X.J.; Xie, L.H.; Yu, C.B.; Wu, Y.F.; Xing, L. Identification of suitable reference genes in leaves and roots of rapeseed (Brassica napus L.) under different nutrient deficiencies. J. Integr. Agric. 2017, 16, 809-819. [CrossRef]

110. Pfaffl, M.W.; Tichopad, A.; Prgomet, C.; Neuvians, T.P. Determination of stable housekeeping genes, differentially regulated target genes and sample integrity: BestKeeper-Excel-based tool using pair-wise correlations. Biotechnol. Lett. 2004, 26, 509-515. [CrossRef]

111. Lamesch, P.; Berardini, T.Z.; Li, D.; Swarbreck, D.; Wilks, C.; Sasidharan, R.; Muller, R.; Dreher, K.; Alexander, D.L.; Garcia-Hernandez, M.; et al. The Arabidopsis Information Resource (TAIR): Improved gene annotation and new tools. Nucleic Acids Res. 2012, 40, D1202-D1210. [CrossRef]

112. Bardou, P.; Mariette, J.; Escudié, F.; Djemiel, C.; Klopp, C. Jvenn: An interactive Venn diagram viewer. BMC Bioinformatics 2014, 15, 293. [CrossRef]

113. Howe, E.; Holton, K.; Nair, S.; Schlauch, D.; Sinha, R.; Quackenbush, J. MeV: MultiExperiment viewer. In Biomedical Informatics for Cancer Research; Springer: Boston, MA, USA, 2010; pp. 267-277.

114. Pathan, M.; Keerthikumar, S.; Ang, C.S.; Gangoda, L.; Quek, C.Y.J.; Williamson, N.A.; Mouradov, D.; Sieber, O.M.; Simpson, R.J.; Salim, A.; et al. FunRich: An open access standalone functional enrichment and interaction network analysis tool. Proteomics 2015, 15, 2597-2601. [CrossRef] [PubMed]

Publisher's Note: MDPI stays neutral with regard to jurisdictional claims in published maps and institutional affiliations. 